\title{
Ethnic Diversity and Social Trust
}

\section{Evidence from the Micro-Context}

Dinesen, Peter Thisted; Sønderskov, Kim Mannemar

Published in:

American Sociological Review

DOI:

10.1177/0003122415577989

Publication date:

2015

Document version

Early version, also known as pre-print

Citation for published version (APA):

Dinesen, P. T., \& Sønderskov, K. M. (2015). Ethnic Diversity and Social Trust: Evidence from the Micro-Context.

American Sociological Review, 80(3), 550-573. https://doi.org/10.1177/0003122415577989 


\title{
Ethnic Diversity and Social Trust: Evidence from the Micro-Context
}

Peter Thisted Dinesen* and Kim Mannemar Sønderskov ${ }^{* * \dagger}$

[Forthcoming in American Sociological Review]

\begin{abstract}
In this paper we argue that residential exposure to ethnic diversity reduces social trust. Previous within-country analyses of the relationship between contextual ethnic diversity and trust have been conducted at higher levels of aggregation, concealing substantial variation in actual exposure to ethnic diversity. In contrast, we analyze how ethnic diversity of the immediate micro-context where interethnic exposure is inevitable - affects trust. We do this using Danish survey data linked with register-based data, which enables us to obtain precise measures of the ethnic diversity of each individual's residential surroundings. We focus on contextual diversity within a radius of 80 meters of a given individual, but compare the effect in the micro-context to the impact of diversity in more aggregate contexts. The results show that ethnic diversity in the micro-context affects trust negatively, while the effect vanishes in larger contextual units. This supports the conjecture that interethnic exposure underlies the negative relationship between ethnic diversity in residential contexts and social trust.
\end{abstract}

Keywords: Social trust; ethnic diversity; micro-context; interethnic exposure; national registers.

\footnotetext{
* University of Copenhagen. Corresponding author. Contact information: Department of Political Science, University of Copenhagen, Øster Farimagsgade 5, DK-1353 Copenhagen K, Denmark.

** Aarhus University

${ }^{\dagger}$ Names are listed alphabetically. The authors contributed equally to the paper. The paper has previously been circulated under the title "Ethnic Diversity and Social Trust: The Role of Exposure in the Micro-Context". The authors would like to thank the VELUX foundation, the Carlsberg foundation and the Danish Council for Independent Research (Social Sciences) for generous support for geocoding the survey data employed. Furthermore, they would like to thank participants at the European Consortium for Political Research General Conference 2011, the Midwest Political Science Conference 2012, the Canadian Political Science Conference 2012, the Ethnic Diversity and Social Capital conference at Wissenschaftszentrum Berlin 2013, and the Comparative Politics Workshop at the University of Maryland 2013 for helpful comments.
} 
Over the past decades, Western societies have grown increasingly ethnically diverse as a result of increased immigration. Following this development, a heated debate about the consequences of increased ethnic diversity in the immigrant-receiving societies has taken place. One of the key themes of this debate is the question as to whether social trust - and social cohesion more generally - can be maintained in the face of an increasingly diverse populace (Putnam 2007). Social trust reflects a positive expectation about the trustworthiness of the generalized, abstract other and a person's level of social trust is thus a standard estimate of the trustworthiness of an unknown other (Robinson and Jackson 2001). ${ }^{1}$ The concerns over the potential erosion of this form of trust relate to its multiple positive consequences for collective action, democratic governance and economic performance. At the individual level, social trust is associated with volunteering, donating to charity, tolerance, and other forms of pro-social behavior (Sønderskov 2011; Uslaner 2002) and in the aggregate, societies with a higher density of high-trusters are characterized by more efficient collective decision-making and better democratic government more generally, as well as higher economic growth (Bjørnskov 2009; Knack and Keefer 1997; Knack 2002). Consequently, answering the question about whether ethnic diversity has an adverse effect on trust is of utmost importance for understanding the challenges that increasingly ethnically diverse Western societies are facing.

Exposure to people of different ethnic background is the mechanism typically expected to underlie the relationship between ethnic diversity and social trust, although this is rarely stated explicitly. That is, being in physical proximity to people of different ethnic background is expected to affect people's estimate of the trustworthiness of the generalized other. While multiple contexts including schools, workplaces and religious institutions - may serve as arenas for exposure to people of different ethnic background, residential areas have been the main contextual domains in which the impact of interethnic exposure on trust has been analyzed in the literature. This focus 
probably reflects that the residential context is a universal setting in which almost everyone is exposed to other people on a regular basis.

Following the debate about the consequences of increased ethnic diversity, the last decade has seen a surge in within-country studies scrutinizing the relationship between trust and residential ethnic diversity at various contextual levels (Alesina and Ferrara 2002; Dincer 2011; Dinesen and Sønderskov 2012; Fieldhouse and Cutts 2010; Gijsberts, van der Meer, and Dagevos 2012; Laurence 2011; Letki 2008; Marschall and Stolle 2004; Phan 2008; Putnam 2007; Stolle, Soroka, and Johnston 2008; Sturgis et al. 2011; Uslaner 2012). The results vary, but generally point toward a moderate negative - although sometimes statistically insignificant - relationship (see van der Meer \& Tolsma [2014] for a review).

However, given that the previous intra-country studies have examined the relationship between ethnic diversity and trust in geographically vast residential areas (with municipalities or census-tracts typically being the smallest contextual units), they are of limited value in examining whether interethnic exposure actually underlies the negative impact of ethnic diversity on trust. In the words of Stolle et al. (2008: 60) "diversity measured at the level of country, state, city or even census tract might not accurately reflect the actual experiences (or perceptions) of heterogeneity in people's daily lives." As recent research has suggested that "[F]ailing to measure the aggregate effects at the proper unit of analysis given the hypothesized theoretical mechanisms may in part explain why some contextual effects appear to be small” (Hipp 2007: 677), such inaccurate measurement may well explain the null findings of some of the previous studies. The point is that measures of ethnic diversity in more aggregate contextual units will inevitably be imprecise, concealing substantial variation in ethnic diversity experienced in the immediate surroundings of the residential context. This in turn makes it impossible to infer whether the suggested mechanism, interethnic exposure in residential areas, is in fact what underlies the negative relationship between 
ethnic diversity and social trust found in the literature, or if other mechanisms account for this relationship, e.g. decreasing trust in response to political conflict over immigration-related issues.

Against the backdrop of the shortcomings of studying the relationship between ethnic diversity and trust at high levels of aggregation, the main contribution of this paper is to examine, as the first study, how ethnic diversity in the residential micro-context affects people's level of social trust, and thus explicitly test whether interethnic exposure is driving this relationship. We analyze the relationship between ethnic diversity in the micro-context and trust using nationally representative survey data merged with detailed individual-level data from the national Danish registers. This enables us to calculate precise measures of actual exposure to residential ethnic diversity because the registers contain reliable information about the country of origin of all residents living in very close proximity (down to within 80 meters [87 yards]) of the respondents' residence.

\section{Theoretical background}

The notion that contextual ethnic diversity affects individuals' social trust reflects an experiential perspective on the formation of trust, which posits that people's trust in the generalized other is based on experiences in their social environment (Dinesen 2012; Glanville and Paxton 2007). That is, people's beliefs about the trustworthiness of the generalized other are to some extent flexible and informed by cues from their social surroundings (see Huckfeldt and Sprague [1995] for a similar argument). In broader terms, this notion of trust is related to Gambetta and Hamill's (2005) conception of the decision to trust others as being based on signs about the trustworthiness of the trustee. As we explain below, ethnicity is one such sign and, not least, an immutable one. From this perspective, the central mechanism underlying the diversity-trust nexus is exposure to people of different ethnic background in our daily life. $^{2}$ In this regard, the neighborhood environment 
provides social cues informing our assessment of the trustworthiness of the generalized other through regular exposure to other people; what Cho and Rudolph (2008) have termed "casual observation” (see also Baybeck and McClurg 2005 and Huckfeldt and Sprague 1995: 10).

In the literature, the negative relationship between residential ethnic diversity and trust is often explained with reference to conflict theory or the closely related group threat theory (Blumer 1958; Bobo and Hutchings 1996; Quillian 1995), which essentially posit that exposure to outgroups - especially those with other ethnic background - spurs conflict and competition over scarce resources. While these theories originally predict that conflict leads to out-group prejudice, the negative consequences are assumed to extend to trust in the generalized other when applied to social trust (e.g. Gijsberts et al. 2012; Putnam 2007). However, the tenability of this extension is questionable. First of all, the empirical evidence for a negative relationship between residential ethnic diversity and interethnic prejudice is mixed (Oliver and Wong 2003; Pettigrew and Tropp 2006), which questions the original argument and hence also the extension made with regard to social trust. Second, the theoretical justification for the extension is problematic. While conflict theory predicts that ethnic diversity leads to negative attitudes towards out-group members, it also predicts more positive in-group attitudes in the face of ethnic diversity (Putnam 2007; Tajfel 1981). As both in-group and out-group trust are positively correlated with social trust (Bahry et al. 2005), it is unclear whether the result of increased ethnic diversity in residential areas would be a net increase or decrease in trust in the generalized other. The general point is that the adaptation of conflict theory to the relationship between residential ethnic diversity and social trust is problematic.

Acknowledging the shortcomings of conflict theory, we argue that the negative relationship between ethnic diversity and trust may alternatively be explained with reference to insights from social psychology and related fields. Several studies report a general human tendency to evaluate 
members of other ethnic groups as less trustworthy compared to in-group members. Evidence from trust games in experimental economics shows lower levels of initial trust when the trustee has a different ethnic background than that of the truster (Fershtman and Gneezy 2001). Similarly, studies using cardiovascular or skin conductance responses show higher levels of perceived threat and fear in encounters with opponents of a different ethnic background than the subject (Mendes et al. 2002; Olsson et al. 2005). Socially learned prejudice probably explains part of this tendency (Stanley et. al. 2011), but recent studies also point to its evolutionary roots. These studies show that humans are better at inferring other humans' thoughts, intentions and feelings if the object belongs to their own ethnic group as opposed to other ethnic groups (Adams et al. 2010). The ability to infer the other's intentions is a crucial component in building trust in specific others, and it is also likely to increase empathy (Chaio and Mathur 2010), which feeds back and increases trust in specific others further (Barraza and Zak 2009). Importantly, positive experiences with and trust in specific others affect evaluations of the generalized other positively and thus spill over to social trust (Freitag and Traunmüller 2009; Glanville and Paxton 2007).

Based on the above, a likely explanation for a negative relationship between residential exposure to ethnic diversity and social trust originates in the general disposition to evaluate individuals with different ethnic background as less trustworthy. This disposition exists regardless of the level of ethnic diversity in the residential setting. However, being more heavily exposed to people of different ethnic background leads to lower levels of social trust because ethnic background functions as a social cue about the trustworthiness of specific others, which in turn affect the overall assessment of the generalized other. The crux of this argument is thus that an evolved and/or learned negative out-group bias affects social trust negatively in the face of residential exposure to people of different ethnic background because more diverse contexts provide cues that lead residents to believe that the generalized other is less trustworthy. 
The proposed explanation is a priori free of assumptions about racial, cultural or behavioral differences between ethnic groups (and their implications for conflict and competition between the groups), but such differences may be expected to increase (or decrease) the effect of residential ethnic diversity (Leigh 2006). However, according to our argument, residential ethnic diversity should be negatively related to social trust even without the various noted group differences because of the out-group bias displayed by individuals (see Enos [2014] for a similar argument regarding anti-immigrant attitudes).

On the face of it, the argument predicts a uniform negative effect of ethnic diversity for natives as well as immigrants. However, it seems reasonable to expect the effect to be contingent on the ethnic background of the person exposed to ethnic diversity (Marschall and Stolle 2004; Stolle et al. 2008). To take one obvious example, the fact that natives make up by far the largest share of the population (in most countries) would on average imply a greater familiarity with this group on the part of immigrants, which may dampen the negative out-group bias, and hence the effect of exposure to natives for immigrants. While this potential conditional effect of diversity is interesting, the analyses below only concern the consequences of exposure to diversity for the native population due to a limited number of immigrants in our sample. ${ }^{3}$

\section{Distinguishing exposure from contact}

It is important to distinguish the concept of exposure to people of different ethnic background from the related concept of interethnic contact, which has recently been introduced to research on the consequences of ethnic diversity for trust. Drawing on contact theory from research on prejudice (Allport 1954), this line of research emphasizes how interethnic contact furthers social trust by reducing ethnic stereotypes and, furthermore, potentially moderates the negative impact of contextual ethnic diversity (Stolle et al. 2008; Uslaner 2012). Focusing on attitudes towards 
homelessness, Lee, Farrell, and Link (2004) argue in favor of expanding the term "contact" so as to differentiate between interactions of different intensity. ${ }^{4}$ Most pertinently to the present study, they distinguish between observation "in the course of everyday life" and interaction, which they take to refer to face-to-face interaction. While we employ different terms, we find a similar distinction to be fruitful for our purposes. We thus take interethnic contact to denote more intimate forms of social interactions such as talking to (i.e. having a conversation with) people of different ethnic background, whereas interethnic exposure implies simply "being around" and casually observing people of different ethnic background.

One key difference between interethnic contact and exposure relates to the extent to which they are subject to self-selection. That is, whether individuals themselves self-select into contact with or exposure to people of different ethnic background. In this regard, interethnic exposure is essentially unavoidable in ethnically diverse neighborhoods, while actual interethnic contact is arguably more of a deliberate decision. ${ }^{5}$ Consequently, interethnic exposure in the neighborhood is likely to have greater implications for social trust in the aggregate than interethnic contact because it is pertinent to everyone living in diverse neighborhoods. ${ }^{6}$

While it is important to distinguish interethnic contact from interethnic exposure to gauge their separate effects on social trust, the two might operate in conjunction as suggested by scholars drawing on contact theory (Laurence, 2011; Stolle et al. 2008; Uslaner 2012). Illustratively, in a study from the US, Stolle et al. (2008) show that the extent to which ethnic diversity in the neighborhood erodes trust is moderated by actual contact. To test this idea, we examine whether the (potential) effect of residential interethnic exposure on trust is contingent on interethnic contact. 


\section{Research design}

We test the hypothesis that exposure to people of different ethnic background influences natives' social trust using data from Denmark. More specifically, we combine representative survey data on social trust from the Danish part of the European Social Survey (ESS) with contextual data on ethnic diversity from the national Danish registers maintained by Statistics Denmark. The registers contain very detailed and up-to-date (anonymized) information about all individuals legally residing in Denmark, including their country of origin, the geographical location of their residence, and a range of other characteristics. Hence, it is possible to locate all individuals by their address in the registers and to identify exactly how far apart everyone lives. Using these data, we have calculated the geodesic distance (in intervals of 10 meters) between each respondent in the ESS and all individuals living in the 20,000 nearest households. By drawing a circle with a given radius around each respondent and subsequently calculating contextual measures of ethnic diversity based on the country of origin of the other individuals living within that circle, we obtain an individualized contextual measure of diversity for each respondent.

To measure interethnic exposure we calculate the ethnic diversity of a circle with a radius of 80 meters around each respondent. The 80 meter context is well-suited for tapping actual exposure because it is a narrow geographic area, which at the same time constitutes a meaningful social context as a substantial number of (other) individuals live within this radius (86 on average in our data). ${ }^{7}$ That said, the 80 meter context is of course somewhat arbitrary in the sense that contexts with a radius of 90 or a 100 meters could equally well serve as micro-context. However, because we can flexibly vary the size of the context, we can examine exactly how the results vary with the specific radius chosen. Specifically, our data enable us to expand the measure of contextual diversity beyond the immediate neighborhood (up to 2,500 meters [2734 yards]). ${ }^{8}$ As we explain below, expanding the context beyond the micro-context serves the important theoretical purpose of 
substantiating interethnic exposure as the underlying mechanism linking residential ethnic diversity and social trust.

Our measure of contextual ethnic diversity represents an important improvement over previously employed measures for several reasons. Most importantly, since this measure captures ethnic diversity in the micro-context, it taps actual exposure to ethnic diversity because individuals can hardly refrain from being exposed to their (diverse) neighbors in their immediate residential surroundings. This in turn provides a direct and critical test of the proposition that interethnic exposure is the mechanism linking contextual ethnic diversity and trust. This stands in contrast to previous studies of the diversity-trust nexus that have relied on highly aggregate contextual data on diversity, which are likely to be poor reflections of the diversity actually experienced in residential areas. Specifically, previous studies have all used aggregate data from administrative entities (e.g. municipalities or census tracts) when assigning contextual diversity to a given respondent. This approach is problematic because it does not locate where each respondent lives within a large contextual unit and one therefore remains agnostic about whether the aggregate level of diversity in this unit corresponds to what individuals experience in their immediate surroundings (see Hipp [2007] for a similar point regarding structural neighborhood characteristics; see also Sampson [2012]). For example, within ethnically diverse municipalities or census tracts, ethnically homogenous enclaves consisting primarily of people with the same ethnic background often exist. Residents in such enclaves are hardly exposed to ethnic diversity in their immediate neighborhood, although the aggregate measure suggests otherwise.

Another related source of measurement error when measuring interethnic exposure using highly aggregate data is that one cannot infer from these data whether an individual lives in the center of a given contextual unit or on the border of this unit and another one. This is especially problematic in more heavily populated areas, where the boundaries of administrative units are likely 
to be somewhat arbitrary. For individuals living on the border between two (or more) contextual units, ethnic diversity measured in the administrative unit in which they reside may over- or underestimate the exposure to ethnic diversity that they actually experience.

The general point is that the existing measures of ethnic diversity in rather aggregate contextual units constitute inaccurate portraits of the diversity individuals experience in their immediate surroundings and are therefore ill-suited for examining whether interethnic exposure is the mechanism explaining the impact of diversity on trust. Conversely, using data on the ethnic diversity of the immediate residential surroundings of individuals allows for a more direct and valid test of whether interethnic exposure affects social trust because individuals are inevitably exposed to people of different ethnicity in ethnically diverse micro-contexts. If we find no effect using these data, it suggests that other mechanisms than interethnic exposure accounts for the empirical relationship between contextual ethnic diversity and trust.

As noted, the data also allow us to vary the level of contextual aggregation in the analyses from contexts with radii of 80 meters up to 2,500 meters. Hence, we follow Hipp's (2007: 675) recommendation that "a more ideal approach would flexibly aggregate the structural characteristics to varying geographic sized areas, rather than just the block or tract". As a consequence, we can further validate whether interethnic exposure is in fact the mechanism linking diversity to trust by comparing the impact of ethnic diversity on trust at various levels of contextual aggregation. If exposure drives the relationship, we would expect the impact of diversity on trust to be found only in the immediate surroundings, where interethnic exposure is inevitable. At higher levels of aggregation, contextual ethnic diversity becomes an increasingly inaccurate measure of actual exposure due to random measurement error. This would lead to a larger standard error of the estimated effect of diversity on trust, and likely also to the estimate being biased towards zero as a result of attenuation bias (Wooldridge 2013: 310-12). Conversely, if other mechanisms, operating in 
more aggregate contexts, explain the relationship, we should not see higher standard errors or attenuation bias at higher levels of aggregation. Relatedly, Putnam (2007) reports findings from the US substantiating the idea that the impact of ethnic diversity on trust is more likely to emerge when measured in less aggregate contextual units (census-tracts rather than counties). However, compared to this and other studies (Phan 2008), which analyze contexts of different size at quite aggregate levels, we can systematically vary the context size from the micro-context to more aggregate surroundings.

\section{The Danish context}

Our primary purpose is theory testing in the sense that we, by means of the best available data, wish to test the notion that interethnic exposure is the underlying mechanism linking ethnic diversity and trust. To our knowledge, the data best suited for this purpose are the Danish data described above. However, the test would obviously be of even greater value if the results could be expected to generalize to other countries (i.e. are externally valid). We believe there are good reasons to expect this to be the case as Denmark is fairly representative of Western European countries on a number of dimensions potentially relevant for the relationship between ethnic diversity and trust. First, immigration trends in Denmark are broadly in line with those observed in many other Western European countries as illustrated in Figure S1 in the online supplement. 8.7 percent of the Danish population was born abroad, which is slightly below the current Western European average (12.9 percent), thus testifying to a demographic shift resembling that taking place in other Western European countries. Second, anti-immigrant/foreigner sentiments in Denmark are also close to the Western European average as is reflected in Figure S2 in the online supplement (see also Semyonov, Moshe and Gorodzeisky 2006 for a similar finding predating the period studied here). This is reassuring for the transferability of our findings to other Western European countries as a 
particularly negative opinion climate in Denmark may have implied that the Danish setting would be more conducive to observing a negative effect of ethnic diversity on trust. Similarly, the presence of a populist radical right party (the Danish People's Party) as a political manifestation of anti-immigrant attitudes is also parallel to what is found in most other Western European countries (Carter 2005; Mudde 2013).

Hence, because Denmark is similar to other Western European countries with regard to the demographic phenomenon studied, increased ethnic diversity induced by immigration, as well as the auxiliary opinion climate at the mass and the elite level, we would, prima facie, expect the patterns found in Denmark to be reflective of the relationship in similar Western European contexts.

\section{The survey data, measures and specifications}

We utilize the first five rounds of the Danish version of the European Social Survey (ESS) conducted in 2002/3, 2004/5, 2006/7, 2008/9 and 2010/11. The ESS is generally held to be a highly valid and reliable data source for survey data on political and social attitudes in Europe (Norris 2004). The respondents in the Danish version of the ESS were randomly sampled from the national civil registry and their civil registration numbers were retained by the data collection agency. This allows us to link individual-level and contextual information from the Danish national registers to each respondent. ${ }^{9}$

\section{The dependent variable: Social trust}

Social trust is measured by the widely used and validated three-item scale (Reeskens and Hooghe 2008; Zmerli and Newton 2008) (see wording in Table S1 in the online supplement). The three items offer a reliable scale of social trust with reasonably strong internal coherence across the five waves $($ Cronbach's alpha $=0.71)$. The mean score on the trust scale, ranging from 0 to 10 , is 6.82 $($ std. dev. $=1.53)$ across all waves. 
The independent variable: Three measures of ethnic diversity

As noted earlier, the national registers contain information about addresses and the country of origin of everyone residing in Denmark and therefore allow us to generate flexible contextual measures of ethnic diversity. In the registers, each individual is classified as native Danish, immigrant (i.e. first generation immigrant) or descendant of immigrants (i.e. second generation immigrant) according to the definition by Statistics Denmark (Ministeriet for Flygtninge, Indvandrere og Integration 2009). A person having at least one parent who was born in Denmark and who holds Danish citizenship is classified as being native Danish regardless of whether (s)he was actually born in Denmark and/or holds Danish citizenship. For people who do not meet these criteria, individuals born outside of Denmark are considered (first generation) immigrants, whereas individuals with parents born outside of Denmark are classified as descendants (second generation immigrants). ${ }^{10}$ Furthermore, the registers also contain information about immigrants' country of origin (and similarly for the parents of descendants), thus allowing for making fine-grained ethnic distinctions when calculating diversity measures. ${ }^{11}$

We employ three measures of ethnic diversity: ethnic fragmentation in terms of the number and relative size of various ethnic groups in a given contextual unit, and two measures of ethnic concentration, namely the share of immigrants and the share of non-Western immigrants. The latter measure is included as non-Western immigrants constitute the group differing most from the native population (ethnically as well as culturally) and over which most contention has occurred. The three measures are operationalized as follows: 
- Ethnic fragmentation: Operationalized as 1 - the Herfindahl-index:

Ethnic fragmentation $_{j}=1-\sum_{i=1}^{N} s_{i j}^{2}$

where $s_{i j}$ is the concentration of the ethnic group $i(\mathrm{i}=1 \ldots N)$ in context $j$. Ethnic group is operationalized as country of origin.

- Concentration of immigrants: The share of immigrants and descendants.

- Concentration of non-Western immigrants: The share of immigrants and descendants not originating in the EU-15, Iceland, Norway, Switzerland, the European micro-states, The United States, Canada, Australia, and New Zealand.

The three measures are highly correlated (Pearson's $r$ of 0.93 or higher) and therefore they are included in separate models. The point of the analysis is thus to probe the robustness of the relationship across different measures of ethnic diversity rather than distinguish between these and their implied mechanism (Schaeffer 2013).

Figure 1 displays the distribution of the three measures of ethnic diversity in the microcontext (within a radius of 80 meters) of the respondents. It shows that most native respondents live in micro-contexts that are not particularly diverse. To take an example, $75 \%$ of the respondents live in a micro-context with less than $10 \%$ immigrants. At the same time, however, there is large variation in ethnic diversity across micro-contexts and a number of respondents live in highly ethnically diverse settings.

[Figure 1 about here]

\section{Control variables}

In order to minimize confounding of the relationship between contextual ethnic diversity and trust we include a range of individual-level and contextual control variables in the estimated models. As 
emphasized in recent studies (Letki 2008; Phan 2008; Sampson \& Graif 2009, Sturgis et al. 2011), ethnic diversity and social trust co-vary with the broader social - and especially socioeconomic environment. Controlling for these aspects of the neighborhood environment is thus paramount in order to isolate the impact of ethnic diversity on trust. Specifically, we include contextual (aggregate) measures of income, unemployment, education, single-parent households and home ownership in order to examine whether it is socioeconomic deprivation in the residential setting rather than ethnic diversity (or both) that shape trust. Similarly, we control for economic inequality of the contextual unit as inequality is generally regarded as an important predictor of trust (Rothstein and Uslaner 2005; Uslaner 2002). We also include a measure of contextual crime, as unsafe neighborhoods may affect residential choice (and hence diversity of the context) as well as trust (Sturgis et al. 2011). Residential turnover has been found to inhibit the development of related forms of trust (Laurence 2009; but see Sampson and Graif 2009) and is therefore also included in the models. Finally, we also include the population density of a given contextual unit. As immigrants generally live in larger cities with higher population density, we include this variable to ascertain that any observed effect of ethnic diversity on trust cannot be attributed to ethnically diverse contexts being more populous than less diverse contexts. ${ }^{12}$ This also implies that a person's residential context (including the ethnic composition) is not contingent on the absolute number of people living there. Similar to the ethnic diversity measures, all other contextual variables are derived from the national registers based on information about the people living within a given radius (the same as the diversity measure) of a respondent in the survey. Coding of and descriptive statistics for all control variables can be found in Table S1 in the online supplement.

We also include several individual-level control variables that are standard predictors of trust (see, e.g., Alesina and Ferrara 2002; Li, Pickles, and Savage 2005; Uslaner 2002). They are included to minimize bias from self-selection that may occur if individuals sort into residential 
locations based on such individual-level characteristics. Specifically, we include gender, age, education, personal disposable income, unemployment, cohabitation status, length of residence at the current address, being a victim of crime, institutional trust, and life satisfaction. Although some of these predictors, especially institutional trust and life satisfaction, may be endogenous to social trust, we opted for including them in the model to provide a conservative test of the impact of ethnic diversity on trust (i.e. to avoid confounding by any individual-level variable). Finally, we include survey round fixed effects to take differences between the five waves not captured by the other variables in the model into account. Despite having included a very rich set of individual-level control variables, self-selection cannot be completely ruled out and we therefore return to this issue below.

\section{Analysis}

We report the results from the empirical analysis in two steps. First, in Table 1, we report OLS ${ }^{13}$ regression analyses of how social trust is affected by the three measures of ethnic diversity of the micro-context (defined as within 80 meters of the individual). ${ }^{14}$ Second, we provide a graphic presentation of the impact of the three measures of ethnic diversity at contextual levels ranging from the least aggregate (within 80 meters of the individual) to the most aggregate (within 2,500 meters of the individual) in our data. This illustrates how the impact of ethnic diversity varies with different levels of contextual aggregation and thus tests the notion that interethnic exposure underlies the relationship between diversity and trust.

The results displayed in Table 1 provide clear evidence that diversity in the micro-context affects social trust negatively as we observe a significant negative relationship for all three measures of diversity. The predicted level of trust is, ceteris paribus, roughly 0.30 point lower among individuals living in a micro-context with 50 percent immigrants or non-Western immigrants 
than among individuals living in a context with no immigrants. As the trust measure is scaled between 0 and 10, this difference suggests a moderate effect of concentration of (non-Western) immigrants in the micro-context. A change in the level of ethnic fragmentation from 0 to 0.5 is predicted to reduce trust by 0.21 point on the trust scale, but given that the scale of ethnic fragmentation is different than for the concentration measures, the effects are not directly comparable. Being based on very sizable changes in the ethnic composition of the micro-context, these effects are arguably fairly modest. If we instead use the increase in the share of immigrants at the national level from 1980 to 2010 (6 percentage points), the predicted drop in social trust is only 0.04 (based on Model 2). Similarly, a one standard deviation increase in ethnic diversity leads to a predicted reduction in trust of 0.06 points (across all diversity measures). The effect is, however, non-negligible as it corresponds to the partial effect of around one year of education, which is one of the most important correlates of trust at the individual level (Uslaner 2002; Helliwell and Putnam 2007).

Looking at the contextual control variables, we note that the mean level of education is the only other contextual variable having a significant effect on trust: living among better-educated neighbors apparently furthers social trust. The effect of a one standard deviation change in contextual education is comparable to that of diversity $(0.05 / 0.06$ vs. 0.06$)$. The remaining contextual variables are all insignificant. Importantly, this is not an artifact of multicollinearity as the variance inflation factor (VIF) for the variables in our models is 2.77 or less. ${ }^{15}$ Hence, contrary to a number of analyses focusing on trust and related aspects of social cohesion in more aggregate contexts (Laurence 2011; Letki 2008; Phan 2008; Sampson and Graif 2009; Sturgis et al. 2011), our results suggest that ethnic diversity is one of the most important (micro-)contextual factors shaping social trust. 
Turning to the individual-level control variables, we mostly see a confirmation of well-known patterns from previous research. Being female, older and better educated is associated with higher trust. The potentially endogenous variables, institutional trust and life satisfaction, are both strongly, positively associated with trust, while none of the remaining controls reaches significance.

In conclusion, the fact that our three measures of residential ethnic diversity emerge as significant predictors of trust in rich models, controlling for other prominent explanations, is strong evidence that ethnic diversity in the micro-context has an independent negative impact on social trust, which cannot be explained by neither contextual socioeconomic deprivation or crime, nor by individual-level characteristics.

[Table 1 about here]

At this point we have shown that ethnic diversity of the immediate micro-context shapes trust negatively. While this analysis provides unprecedented support for interethnic exposure being the mechanism linking diversity to trust, the data allow us to test this hypothesis even more rigorously. Below we compare the impact of ethnic diversity across contextual units of varying size. If interethnic exposure is the driver of the relationship, we would expect the negative impact of ethnic diversity on trust to be strongest in the more immediate surroundings, where exposure is inevitable, and to be diluted (and estimated less precisely) at more aggregate contextual levels, where exposure is captured much less accurately. In Figure 2 we have illustrated the estimated effect of ethnic diversity on trust across different levels of contextual aggregation. The figure displays the effect of a given measure of ethnic diversity based on regressions with similar specifications as in Table 1 with contextual control variables measured in contexts of the same size as the diversity variables.

[Figure 2 about here] 
The figure shows that the effect of ethnic diversity differs markedly when measured at the lowest (80 meters) and the highest levels (2,500 meters) of aggregation in our data. For all three measures of ethnic diversity we see the same pattern: ethnic diversity has a significant negative impact on trust at low levels of aggregation (up to 180 meters [197 yards]), after which the estimate gradually goes towards zero and becomes less precise (as indicated by the increasing standard errors). In other words, in the micro-context, where interethnic exposure is captured more accurately, ethnic diversity has a negative impact on trust, whereas this effect is diluted in contexts of higher aggregation, where exposure is arguably measured more crudely. This supports the notion that interethnic exposure is the mechanism accounting for the negative impact of ethnic diversity on trust. As for the context size consequential for trust, it is interesting to observe that a radius somewhere between 180 and 250 meters seems to be the cut-off point after which the effect of ethnic diversity starts to wane. This is an important result as it shows that ethnic diversity must be measured in quite disaggregate contexts in order to detect an effect on trust, which may also explain some of the insignificant effects found in previous studies at higher levels of aggregation.

Is the negative impact of exposure to ethnic diversity moderated by contact?

As noted earlier, a recent line of research has focused on how the impact of ethnic diversity on trust may be moderated by intense contact with people of different ethnic background. If there is a cushioning effect of interethnic contact, this would suggest that the negative consequences of interethnic exposure does not reflect deep-held negative dispositions toward ethnic out-groups, but instead seem to be malleable. It is important to point out that moderation by interethnic contact - or any other variable - does not compromise the finding that there is a negative impact of ethnic diversity on trust on average. However, the effect of diversity on trust may be heterogeneous in the sense that the overall negative effect may conceal stronger effects for some people, e.g. those without interethnic contact (or other characteristics), and, by implication, weaker effects for others. 
Our data allow us to gain some purchase on the notion that interethnic contact moderates the impact of interethnic exposure on trust as the first wave of ESS holds (separate) measures of having immigrant friends or colleagues (see Table S1 in the online supplement for details). Admittedly, these measures may not reflect interethnic contact per se, but they would arguably tend to tap this form of contact. The two measures complement each other well in the sense that friendship is an intense form of personal contact, which is less common (more than $50 \%$ of the respondents indicate having no immigrant friends) and arguably more self-selected, whereas contact in the workplace is more pronounced and less self-selected, but also less intense. Ideally, one would also have a measure of actual interethnic contact in the neighborhood, but this does not exist in the survey.

To test the idea that interethnic contact moderates interethnic exposure we followed the approach of Stolle et al. (2008) and included the two measures of contact (measured categorically) as well as interactions between these variables and each of the measures of ethnic diversity in the micro-context (measured within a radius of 80 meters of the respondent). None of the interaction terms were significant, nor were they jointly significant. This suggests that interethnic contact does not - at least not as measured in the ESS - moderate the negative impact of ethnic diversity of the micro-context on social trust. It is also worth noting that including only the constitutive terms of the two contact measures, our point estimate of the impact of contextual ethnic diversity on trust remain unaffected, which corroborates Laurence's (2011) findings regarding neighborhood trust in Britain. This suggests that the effect of interethnic exposure is not mediated by interethnic contact, and it also underlines that interethnic exposure and contact are empirically different phenomena. In conclusion, while we cannot assess the potential moderation by interethnic contact in full detail, the data at hand suggest that there is an unconditional negative impact of interethnic exposure in the micro-context on social trust. 
Is the effect of ethnic diversity heterogeneous?

In addition to interethnic contact, other potential moderators of the influence of ethnic diversity have also been suggested in the literature. Two categories of moderators appear particularly relevant with regard to the impact of ethnic diversity on trust: neighborhood-related factors, which may moderate the experience of ethnic diversity in this context, and individual-level characteristics pertaining to resources and vulnerability.

The extent to which people's experience of ethnic diversity in the neighborhood channels into mistrust may likely be conditioned by other aspects related to the neighborhood context. Of particular relevance is the individual's length of residence in the neighborhood. Given the negative impact of ethnic diversity, one may expect that having spent longer time in more ethnically diverse surroundings would tend to magnify this effect. Conversely, in line with contact theory, one may also expect the negative effect of ethnic diversity to wither over time as people familiarize themselves and (maybe) become comfortable with diverse surroundings. To test these predictions we interacted the diversity variables with length of residence and found no support for either. ${ }^{16}$ Hence, the impact of ethnic diversity on trust does not significantly vary with length of residence in the neighborhood. Because the effect of diversity operates independently of cumulative experiences in the neighborhood context, this may implicitly be taken as tentative evidence of our theory that a deep-held negative out-group bias triggers the negative impact of interethnic exposure on trust in the micro-context. However, given that length of residence may also reflect self-selection when using observational data, further evidence is needed to substantiate this assertion more fully.

Another potential neighborhood moderator is the general social composition of this context. As several authors have suggested, economic deprivation and economic inequality (Putnam 2007; Sturgis et al. 2011), may be expected to amplify the negative effects of ethnic diversity on trust. Cues regarding other people's ethnicity perhaps become more salient, and thus more consequential 
for trust, when resources are scarce or unevenly distributed. To assess this, we interacted contextual income inequality and mean disposable income with the measures of ethnic diversity. In line with the results by Putnam (2007) and Sturgis et al. (2011) we found no evidence that the impact of ethnic diversity varies by neither neighborhood income nor inequality.

An additional class of potential moderators of the effect of ethnic diversity is individual resources and vulnerability. One may expect the resourceful and less vulnerable to be less sensitive to negative experiences including that of interethnic exposure in the micro-context. Using two measures of resources - education and income - and one of vulnerability - victimization - from our models, we find no evidence of moderation by these factors. We also examined heterogeneous effects by gender and age, two potential demographic indicators of vulnerability, but in accordance with Putnam (2007) we found no differential effects for different groups.

The conclusion based on the tests above is thus that the effect of ethnic diversity on trust is strikingly universal in the sense that it does not vary significantly by factors related to neither the neighborhood nor the individual. In other words, natives appear to respond uniformly negative to interethnic exposure in the micro-context. This may suggest that the negative relationship comes about because of a dispositional skepticism towards people of other ethnic background.

\section{Do the results reflect self-selection?}

The inherent problem in all analyses of the relationship between contextual characteristics and individual-level attitudes using observational data is that it is not possible to rule out that a correlation reflects self-selection of individuals into certain contexts based on these attitudes, rather than a causal effect of living in these contexts. In other words, the estimated effect of microcontextual ethnic diversity on trust may be biased because of self-selection.

Putnam (2007) and Rudolph and Popp (2010), however, argue that self-selection seems prima facie implausible as an explanation for an observed negative relationship between ethnic diversity 
and trust as this would imply that the least trusting individuals would locate themselves in the most diverse environments. They argue that the opposite is more plausible, namely that the least trusting would choose to live in the least diverse environments. This in turn implies that, if biased, the impact of contextual ethnic diversity on trust is likely underestimated (i.e. more negative than our results suggest). However, while self-selection based on trust may be an implausible explanation for the negative relationship between diversity and trust, it seems likely that unobserved factors simultaneously affecting both residential choice and trust (e.g. a deep-held preference for homogenous social surroundings [i.e. homophily; cf. McPherson, Smith-Lovin and Cook 2001] or fundamental dispositions towards out-groups) could potentially confound the relationship, although the potential bias from this form of self-selection is arguably reduced by the inclusion of a rich set of control variables in our models. Therefore, in an attempt to assess the magnitude of the potential self-selection, we conducted a number of empirical tests comparable to those employed in previous studies addressing this problem in related research. ${ }^{17}$

First, equivalent to the strategy employed by Oliver and Wong (2003), we included a variable tapping respondents' preferences for the ethnic mix of the ideal living area (see coding in Table S1 in the online supplement). This variable was only measured in the first round of the ESS and thus we had to limit the analysis to this subset of the sample. By including preference for ethnic mix of the ideal living area we take into account the fact that this inclination may affect both residential choice and trust and thus confound the relationship between the two. The results of the analysis show that this is not the case, however, as the estimated effect of ethnic diversity on trust is unaffected by including the measure of preferred living area. In other words, the negative impact of ethnic diversity on trust does not appear to reflect a preference for living in homogenous surroundings. 
As a second strategy for assessing self-selection, we followed the approach of Putnam (2007) and Rudolph and Popp (2010) in examining how patterns of relocating and staying put in residential areas correlate with trust. We examined whether trusting individuals are more likely to self-select out of ethnically diverse micro-contexts, as this would imply that the lower levels of trust found in more diverse areas are a result of this selection process. This was assessed by means of estimating a model for the propensity to change residence (based on residential data from the registers) within three years after being interviewed in the ESS. In the model we included individual-level trust and an interaction term between trust and contextual ethnic diversity along with the other covariates in the models reported in Table 1 . The results showed no higher propensity for trusting individuals to relocate from more ethnically diverse areas and hence there is no evidence indicating that this form of self-selection is driving our results. Similarly, the finding that the impact of ethnic diversity on trust does not depend on length of residence in the context (reported in the previous section) indirectly indicates that self-selection based on resources cannot explain the negative impact of ethnic diversity on trust. If staying put reflects not having the means for moving, this group should, ceteris paribus, be less self-selected, and, by implication, we would have expected a stronger negative effect of ethnic diversity on trust for those staying. ${ }^{18}$

In sum, while we cannot rule out self-election as a potential explanation for the observed negative relationship between micro-contextual ethnic diversity and social trust given the observational nature of our data, empirical tests provide no indication that this is a likely interpretation of the results. This strengthens our faith that interethnic exposure does in fact have a negative impact on trust. 


\section{Conclusion and discussion}

In this paper we have tested whether ethnic diversity of the immediate residential surroundings has an impact on social trust using survey data merged with data from the national Danish registers. The results show that ethnic diversity of the micro-context - measured within a radius of 80 meters of a person - has a statistically significant negative impact on social trust, controlling for a large number of potentially confounding variables. When expanding the size of the context, the effect of ethnic diversity is diluted, and we take this as an indication that interethnic exposure - which is inevitable in the micro-context, but not in more aggregate contexts - is the mechanism underlying the negative relationship between residential ethnic diversity and trust.

Our results suggest that coupling survey data on trust with rich contextual data on ethnic diversity in individualized contexts of small size is indeed fruitful, not least because this allows for a more direct assessment of the mechanism - interethnic exposure - expected to underlie this relationship. Not doing so, and continuing to build on measures of ethnic diversity within administrative units at rather aggregate contextual levels, is likely to lead to erroneous inference about the impact of ethnic diversity on trust as our results clearly indicate. However, the consequences of not analyzing appropriate contextual-level data extend far beyond that of the specific research question analyzed here. Dating back more than a century, there has been a massive interest in the question of how residential context affects attitudes, perceptions and behaviors. Scholars have examined how living among others with certain characteristics affects an individual's propensity to participate in politics (Cho and Rudolph 2008), attitudes toward out-groups (Bobo and Hutchings 1996) and opinions about redistribution (Luttmer 2001), to take just a few examples. Our results imply that revisiting these questions using individualized, flexibly aggregated microcontextual data is a promising avenue for further research. This would lead to a better understanding of the mechanisms underlying the relationship between contextual characteristics and individual- 
level outcomes, and ultimately provide new insights into the social contingency of individual behavior and attitudes.

While we have argued that our study holds several important advantages over previous research investigating the relationship between ethnic diversity and trust, we should also acknowledge that our study is only one step in the direction of gaining a better understanding of this question. Multiple steps along different lines have to be taken to push the research agenda further forward. Below we consider some of the paths that we believe would contribute to this development.

Theoretically, we have suggested that the interaction between a dispositional out-group mistrust and contextual social cues in terms of exposure to people of different ethnic background in residential contexts accounts for the negative effect of contextual ethnic diversity on trust. However, we still need to know in more detail what it is exactly about interethnic exposure that lowers trust. Although empirically challenging, a logical next step would be to follow the lead of Schaeffer (2013) and try to parse out the various out-group cues embodied in contextual interethnic exposure - e.g. racial, cultural and behavioral differences between ethnic groups - and examine their importance for trust.

Directly related to the approach employed in this paper, the question of the specification of the appropriate contextual unit consequential for trust and other attitudes, still looms large in the literature. We have argued and empirically verified that using individual-level data to generate flexible "objective" contextual measures is a methodological advance in this regard. At the same time, this approach could arguably profit from being supplemented with a "subjective" approach, such as that by Wong et al. (2012), in which individuals themselves define their (perceived) neighborhood. A combination of the two approaches would shed light on the forces in individuals' 
residential environment - subjectively experienced or operating subconsciously - that shape their trust in other people.

In methodological terms, a main challenge is to further substantiate causal claims by addressing the issue of potential self-selection of individuals into more or less ethnically diverse micro-contexts. Natural experiments, e.g. in terms of exogenous changes in contextual ethnic composition due to abolishment of public housing (Enos Forthcoming), or field experiments (Enos 2014) would arguably provide further leverage for bypassing issues of self-selection and thus drawing inference about the causal impact of contextual ethnic diversity on trust.

Finally, another question that warrants further attention is whether the negative impact of micro-contextual interethnic exposure on trust found in the Danish setting generalizes to other contexts - that is, is externally valid. As argued earlier, it seems, prima facie, reasonable to expect a similar relationship in Western European countries that have experienced similar immigrationinduced increases in ethnic diversity and share a comparable opinion climate at the mass and the elite level. It appears more problematic to infer from the Danish context to countries with different immigration trajectories and histories of ethnic and racial relations. That said, the study that comes closest to ours in terms of scrutinizing the relationship between micro-contextual ethnic diversity and social trust was conducted in New Zealand, where a similar negative relationship was found across proximate local contexts (so-called meshblock units) (Sibley et al. 2013). Thus, while not having the same advantages with regard to examining interethnic exposure (the size of the contexts are not fixed or flexibly varied), and therefore not strictly comparable to our study, the best available evidence suggests that the negative relationship found in Denmark can also be reproduced in a developed country with a rather different immigration history.

As a logical conclusion of our paper, we should stress that our results have substantial implications for the discussion about the consequences of immigration for social cohesion in the 
destination countries, and for which policy alternatives that may be effective in addressing the suggested negative consequences. In this regard, it is important not to overstate the impact of contextual ethnic diversity when compared to other factors shaping social trust. The Danish experience is illustrative in this regard. Over the past 30 years the level of ethnic diversity in Denmark has increased by about three-fold when measured as the share of immigrants (and about six-fold when measured as the share of non-Western immigrants), while trust in the same period has increased from just about 50 percent expressing social trust in 1979 to almost 80 percent in 2009 - a level of trust unparalleled anywhere in the world but in the other Nordic countries (Sønderskov and Dinesen Forthcoming). However, at the same time, the increased ethnic diversity has been found to be associated with lower levels of trust across Danish municipalities (Dinesen and Sønderskov 2012). Hence, ethnic diversity has a negative impact on trust, but this is clearly overshadowed by other forces driving trust to unseen heights in the Danish context. This means that while we should obviously take the negative consequences of ethnic diversity for trust seriously, we should not lose sight of other factors - most importantly education at the individual level (Uslaner 2002; Helliwell and Putnam 2007; though see Oskarsson et al. 2014) and institutional quality at the society level (Rothstein and Stolle 2008; Dinesen 2013; Sønderskov and Dinesen Forthcoming) - which matter more for people's social trust. By strengthening these factors, governments would most likely counterbalance the negative impact of ethnic diversity on trust. 


\section{Notes}

${ }^{1}$ We keep in line with most of the literature by using the term "social trust" although the more precise term is arguably "generalized social trust", which underlines that this is the specific type of social trust associated with trust in other people in general. This stands in contrast to more "contextualized" conceptions of trust emphasizing trust in a "specific person in a particular situation" (Cook and Gerbasi 2009: 222) or what Sampson and Graif (2009: 182) call "grounded or working trust". Similarly, the generalized form of social trust is different from trust in well-known, specific others (particularized trust), and trust in specific groups (Freitag \& Bauer 2013).

${ }^{2}$ We employ the term "mechanism" in line with Gerring (2007: 178), namely as "the pathway or process by which an effect is produced or a purpose is accomplished" (see Hedström and Bearman [2009: 5] for a related definition from analytical sociology).

${ }^{3}$ In addition, the immigrants in the sample are likely to be selected (the survey was only asked in Danish) and generally a quite heterogeneous group in terms of factors that may interact with ethnic diversity (e.g. length of stay and country of origin), which also speaks in favor of limiting the sample to natives only. However, the exclusion of immigrants from the sample does not affect the results markedly as our findings replicate using the full sample (Table S2 in the online supplement reports these results).

${ }^{4}$ To complicate matters somewhat in relation to the present paper, Lee et al. (2004: 43) use the overarching label of "exposure" to differentiate between different types of contact.

${ }^{5}$ While self-selection into neighborhoods of different ethnic diversity based on prior levels of trust is likely (we address this after the analysis), a similar self-selection into actual contact with people of different ethnic background is arguably more pronounced. In other words, the relationship between interethnic exposure and trust is, ceteris paribus, likely to be less plagued by endogeneity than that between contact and trust.

${ }^{6}$ There is also a methodological aspect of the distinction between exposure and contact relating to their measurement. Measuring contact one generally has to rely on self-reported survey measures (Stolle et al. 2008; Uslaner 2012), whereas exposure (at least in our case) can be measured by objective contextual characteristics drawn from official registers. Using self-reported measures of contact from the same survey as the measure of trust will most likely result in an upward bias in the relationship between the two because of common method bias (Podsakoff et al. 2003). That is, the 
relationship would to some extent reflect, e.g., the respondent's mood state when responding to the survey. Conversely, an association between trust and contextual exposure using distinct data sources cannot be caused by common method bias.

${ }^{7}$ However, the narrowest contexts may consist of only a few people in remote areas, which may in turn result in the contextual variables being sensitive to the specific size of the context. Therefore we tried limiting our sample to respondents whose context consists of at least 20 people to probe the robustness of the results. Table S3 in the online supplement reports these results. Evidently, the results remain substantively unchanged compared to those for the full sample reported in the paper, thereby providing evidence that our results are insensitive to the number of people that the contextual measures are based on.

${ }^{8}$ The upper limit of 2,500 meters is the largest context for which we have contextual data for all respondents because the 20,000 nearest households are located within 2,500 meters of respondents in the most densely populated areas.

${ }^{9}$ The survey data used are available from http://www.europeansocialsurvey.org. The survey data merged with register data are not publicly available as the use of the latter is restricted to authorized users by Danish law.

${ }^{10}$ The definition of immigrants and descendants employed by Statistics Denmark also includes refugees and asylum seekers. Hence, throughout the paper, the term "immigrant" also refers to the latter two groups.

${ }^{11}$ Admittedly, immigrants' country of origin is only a proxy for ethnic background and as such our contextual diversity measures do not measure ethnic diversity per se. Nevertheless, this is in line with most previous studies and as such we find it most useful to continue using this terminology. Moreover, national origin is arguably the "objective" measure available in the public registers that corresponds most closely to the mechanism we propose to underlie the relationship between ethnic diversity and trust, namely exposure to identifiable (ethnic) out-groups.

${ }^{12}$ We also tried including respondents' perceived city size in the models. The main results remain insensitive to the inclusion of this variable.

${ }^{13}$ Using OLS regression could yield biased estimates and/or standard errors if people living in close proximity tend to have similar levels of social trust (the existence of spatial autocorrelation), e.g. due to common exposure to unobserved contextual characteristics. Given that we have a random sample from a large, and geographically scattered, population, 
and that we include a rich set of control variables in our models, there is not strong reason to be particularly worried about autocorrelation in this study compared to previous studies (but see Sampson and Graif 2009). As we only have information about the spatial distance between each respondent and the people residing in the 20.000 nearest households, the best test of occurrence of spatial autocorrelation in our data is focusing on the most densely populated area in Denmark, the adjacent municipalities of Copenhagen and Frederiksberg, where a substantial number of respondents reside. This test (carried out in each wave of the survey) suggests that spatial autocorrelation is not a concern as the Moran's $I$ statistics is not significant.

${ }^{14}$ To substantiate that the relationship between the ethnic diversity measures and trust is linear we examined augmented component plus residual plots (see Figure S3 in the online supplement). Similarly to Putnam (2007), we found no evidence of "tipping point" effects or other signs of non-linearity. This is also evidenced by quadratic terms of the ethnic diversity measures being non-significant when added to the models. Moreover, we found no signs of outliers driving the results; excluding respondents with "critical" $(>2 / \sqrt{n})$ DFBETA values for the diversity variables yields slightly larger and more precise effects.

${ }^{15}$ The only exception is contextual crime, which is highly collinear with population density because crime is measured in absolute levels. However, including crime incidents per capita instead does not render the variable significant, nor does it change the relationship between ethnic diversity and trust.

${ }^{16}$ This and subsequent moderation tests were carried out in contexts with a radius of 80 meters.

${ }^{17}$ All the empirical analyses addressing self-selection are carried out on the three indicators of ethnic diversity measured in contexts of a radius of 80 meters.

${ }^{18}$ Following a similar reasoning, we also examined whether there is a differential impact of diversity on trust for wealthy respondents (measured by personal disposable income), who are more prone to self-select into residential areas due to being less economically restricted (Putnam 2007). This is not the case, again pointing to self-selection not driving our results. 


\section{References}

Adams, Reginald B., Nicholas O. Rule, Robert G. Franklin Jr., Elsie Wang, Michael T. Stevenson, Sakiko Yoshikawa, Mitsue Nomura, Wataru Sato, Kestutis Kveraga, and Nalini Ambady. 2010. "Cross-cultural Reading the Mind in the Eyes: An fMRI Investigation." Journal of Cognitive Neuroscience 22(1):97-108.

Alesina, Alberto and Eliana La Ferrara. 2002. "Who trusts others?" Journal of Public Economics $85: 207-34$

Allport, Gordon. W. 1954. The Nature of Prejudice. New York: Basic Books.

Bahry, Donna, Mikhail Kosolapov, Polina Kozyreva, and Rick K. Wilson. 2005. "Ethnicity and trust: Evidence from Russia", American Political Science Review 99(4):521-32.

Baybeck, Brady and Scott D. McClurg. 2005. "What Do They Know and How Do They Know It? An Examination of Citizen Awareness of Context." American Politics Research 33:492-520.

Barraza, Jorge A. and Paul J. Zak. 2009. "Empathy towards Strangers Triggers Oxytocin Release and Subsequent Generosity." Annals of the New York Academy of Sciences 1167:182-9.

Bjørnskov, Christian. 2009. "Economic growth.” pp. 337-53 in Handbook of Social Capital: The Troika of Sociology, Political Science and Economics, edited by Gert T. Svendsen and Gunnar L.H. Svendsen. Cheltenham: Edward Elgar.

Blumer, Herbert. 1958. "Race Prejudice as a Sense of Group Position." The Pacific Sociological Review 1(1):3-7.

Bobo, Lawrence and Vincent L. Hutchings. 1996. "Perceptions of Racial Group Competition: Extending Blumer's Theory of Group Position to a Multiracial Social Context." American Sociological Review 61:951-72. 
Carter, Elisabeth. 2005. The extreme right in Western Europe: Success or failure?. Manchester University Press.

Chiao, Joan Y. and Vani A. Mathur. 2010. “Intergroup Empathy: How Does Race Affect Empathic Neural Responses?" Current Biology 20(11):R478-80.

Cho, Wendy K.T. and Thomas J. Rudolph. 2008. "Emanating Political Participation. Untangling the Spatial Structure behind Participation.” British Journal of Political Science 38(2):273-89.

Cook, Karen S. and Alexandra Gerbasi. 2007. "Trust". pp. 218-39 in The Oxford Handbook of Analytical Sociology, edited by Peter Hedström and Peter Bearman. Oxford: Oxford University Press.

Dincer, Oguzhan C. 2011. "Ethnic Diversity and Trust." Contemporary Economic Policy 29(2):284-93.

Dinesen, Peter T. 2012. "Does Generalized (Dis)Trust Travel? Examining the Impact of Cultural Heritage and Destination-Country Environment on Trust of Immigrants.” Political Psychology 33(4): 495-511.

Dinesen, Peter T. 2013. "Where You Come From or Where You Live? Examining the Cultural and Institutional Explanation of Generalized Trust Using Migration as a Natural Experiment.” European Sociological Review 29(1):114-28.

Dinesen, Peter T. and Kim M. Sønderskov. 2012. "Trust in a time of increasing diversity: On the relationship between ethnic heterogeneity and social trust in Denmark from 1979 until today." Scandinavian Political Studies 35(4):273-94.

Enos, Ryan D. Forthcoming. "What the Demolition of Public Housing Teaches Us About the Impact of Racial Threat on Political Behavior.” American Journal of Political Science. 
Enos, Ryan D. 2014. “Causal effect of intergroup contact on exclusionary attitudes.” Proceedings of the National Academy of Sciences 111(1):3699-704.

Fershtman, Chaim and Uri Gneezy. 2001. "Discrimination in a Segmented Society: An Experimental Approach.” Quarterly Journal of Economics 116(1):351-77.

Fieldhouse, Edward and David Cutts. 2010. "Does Diversity Damage Social Capital? A Comparative Study of Neighbourhood Diversity and Social Capital in the US and Britain.” Canadian Journal of Political Science 43(2):289-318.

Freitag, Markus and Richard Traunmüller. 2009. "Spheres of trust: An empirical analysis of the foundations of particularised and generalised trust." European Journal of Political Research 48(6):782-803.

Freitag, Markus and Paul C Bauer. 2013. "Testing for Measurement Equivalence in Surveys Dimensions of Social Trust across Cultural Contexts." Public Opinion Quarterly 77(S1):24-44.

Gambetta, Diego and Heather Hamill. 2005. Streetwise: How Taxi Drivers Establish Their Customer's Trustworthiness. New York: Russell Sage Foundation.

Gerring, John. 2007. "The Mechanismic Worldview: Thinking Inside the Box." British Journal of Political Science 38(1):161-79.

Glanville, Jennifer L. and Pamela Paxton. 2007. "How Do We Learn to Trust? A Confirmatory Tetrad Analysis of the Sources of Generalized Trust." Social Psychology Quarterly 70(3):23042.

Gijsberts, Mérove, Tom van der Meer, and Jaco Dagevos. 2012. “'Hunkering Down’ in MultiEthnic Neighbourhoods? The Effects of Ethnic Diversity on Dimensions of Social Cohesion.” European Sociological Review 28(4):527-37. 
Hedström, Peter and Peter Bearman. 2009. "What is Analytical Sociology All About? An Introductory Essay". pp. 3-24 in The Oxford Handbook of Analytical Sociology, edited by Peter Hedström and Peter Bearman. Oxford: Oxford University Press.

Helliwell, John F. and Robert D. Putnam. 2007. "Education and Social Capital.” Eastern Economic Journal 33(1):1-19.

Hipp, John R. 2007. "Block, Tract, and Levels of Aggregation: Neighborhood Structure and Crime and Disorder as a Case in Point.” American Sociological Review 72(5):659-80.

Huckfeldt, Robert and John Sprague. 1995. Citizens, Politics, and Social Communication: Information and Influence in an Election Campaign. New York: Cambridge University Press.

Knack, Stephen and Philip Keefer. 1997. "Does Social Capital have an Economic Payoff? A CrossCountry Investigation.” Quarterly Journal of Economics 112(4):1251-88.

Knack, Stephen. 2002. "Social Capital and the Quality of Government: Evidence from the States." American Journal of Political Science 46(4):772-85.

Laurence, James. 2011. "The Effect of Ethnic Diversity and Community Disadvantage on Social Cohesion: A Multi-Level Analysis of Social Capital and Interethnic Relations in UK Communities.” European Sociological Review 27(1):70-89.

Lee, Barrett A., Chad R. Farrell, and Bruce G. Link. 2004. "Revisiting the Contact Hypothesis: The Case of Public Exposure to Homelessness," American Sociological Review 69(1):40-63.

Leigh, Andrew. 2006. “Trust, Inequality and Ethnic Heterogeniety.” The Economic Record 82:268280.

Letki, Natalia. 2008. "Does Diversity Erode Social Cohesion? Social Capital and Race in British Neighbourhoods.” Political Studies 56(1):99-126. 
Li, Yaojun, Andrew Pickles, and Mike Savage. 2005. "Social Capital and Social Trust in Britain." European Sociological Review 21(2):109-23.

Luttmer, Erzo F.P. 2001. "Group loyalty and the taste for redistribution." Journal of Political Economy 109(3):500-28.

Marschall, Melissa J. and Dietlind Stolle. 2004. "Race and the City: Neighborhood Context and the Development of Generalized Trust.” Political Behavior 26(2):125-53.

McPherson, Miller, Lynn Smith-Lovin, and James M. Cook. 2001. "Birds of a Feather: Homophily in Social Networks.” Annual Review of Sociology 27:415-44.

Mendes, Wendy B., Jim Blascovich, Brian Lickel, and Sarah Hunter. 2002. "Challenge and Threat During Social Interactions With White and Black Men.” Personality and Social Psychology Bulletin 28(7):939-52.

Ministeriet for Flygtninge, Indvandrere og Integration. 2009. Tal og fakta - befolkningsstatistik om indvandrere og efterkommere. Copenhagen: Ministeriet for Flygtninge, Indvandrere og Integration.

Mudde, Cas. 2013. “The 2012 Stein Rokkan Lecture. Three decades of populist radical right parties in Western Europe: So what?.” European Journal of Political Research 52:1-19.

Norris, Pippa. 2004. "From the Civic Culture to the Afrobarometer." Newsletter of the American Political Science Association Organized Section in Comparative Politics 15:6-11.

Oliver, J. Eric and Janelle Wong. 2003. "Intergroup Prejudice in Multiethnic Settings.” American Journal of Political Science 47(4):567-82.

Olsson, Andreas, Jeffrey P. Ebert, Mahzarin R. Banaji, and Elizabeth A. Phelps. 2005. "The Role of Social Groups in the Persistence of Learned Fear.” Science 309(29):785-87. 
Oskarsson, Sven, Peter Thisted Dinesen, Christopher T. Dawes, Magnus Johanneson, and Patrik K.E. Magnusson. 2014. "Education and Social Trust: Testing a Causal Hypothesis Using the Discordant Twin-Pair Design.” Mimeo.

Pettigrew, Thomas. F. and Linda R. Tropp. 2006. “A Meta-Analytic Test of Intergroup Contact Theory." Journal of Personality and Social Psychology 90(5):751-83.

Phan, Mai B. 2008. "We're All in This Together: Context, Contacts, and Social Trust in Canada." Analyses of Social Issues and Public Policy 8(1):23-51.

Podsakoff, Philip M., Scott B. MacKenzie, Jeong-Yeon Lee, and Nathan P. Podsakoff. 2003. "Common Method Biases in Behavioral Research: A Critical Review of the Literature and Recommended Remedies.” Journal of Applied Psychology 88(5):879-903.

Putnam, Robert D. 2007. "E Pluribus Unum: Diversity and Community in the Twenty-first Century." Scandinavian Political Studies 30(2):137-74.

Quillian, Lincoln. 1995. "Prejudice as a Response to Perceived Group Threat: Population Composition and Anti-immigrant Racial Prejudice in Europe." American Sociological Review 60:586-611.

Reeskens, Tim and Marc Hooghe. 2008. "Cross-Cultural Measurement Equivalence of Generalized Trust: Evidence from the European Social Survey 2002 and 2004.” Social Indicators Research 85(3):1-18.

Robinson, Robert V. and Elton F. Jackson. 2001. "Is Trust in Others Declining in America? An Age-Period-Cohort Analysis.” Social Science Research 30(1):117-45.

Rothstein, Bo and Dietlind Stolle. 2008. "The State and Social Capital. An Institutional Theory of Generalized Trust." Comparative Politics 40(4):441-60. 
Rothstein, Bo and Eric Uslaner. 2005. "All for All: Equality, Corruption, and Social Trust.” World Politics 58(1):41-72.

Rudolph, Thomas J. and Elizabeth Popp. 2010. "Race, Environment, and Interracial Trust.” Journal of Politics 72(1):74-89.

Sampson, Robert J. 2012. Great American City: Chicago and the Enduring Neighborhood Effect. Chicago: University of Chicago Press.

Sampson, Robert J. and Corina Graif. 2009. "Neighborhood Networks and Processes of Trust". pp. 182-215 in Whom Can We Trust? How Groups, Networks, and Institutions Make Trust Possible, edited by Karen S. Cook, Margaret Levi and Russell Hardin. New York: Russell Sage Foundation.

Schaeffer, Merlin. 2013. "Can competing diversity indices inform us about why ethnic diversity erodes social cohesion? A test of five diversity indices in Germany." Social Science Research 42(3):755-74.

Semyonov, Moshe, Rebeca Raijman and Anastasia Gorodzeisky. 2006. "The Rise of Anti-foreigner Sentiment in European Societies 1988-2000.” American Sociological Review 71(3):426-49.

Sibley, Chris G., John Duckitt, Robin Bergh, Danny Osborne, Ryan Perry, Frank Asbrock, Andrew Robertson, Gavin Armstrong, Marc Stewart Wilson, and Fiona Kate Barlow. 2013. “A Dual Process Model of Attitudes towards Immigration: Person x Residential Area Effects in a National Sample.” Political Psychology 34(4):553-72.

Stanley, Damian A., Peter Sokol-Hessner, Mahzarin R. Banaji, and Elizabeth A. Phelps. 2011. "Implicit race attitudes predict trustworthiness judgments and economic trust decisions." Proceedings of the National Academy of Sciences 108(19):7710-5. 
Stolle, Dietlind, Stuart Soroka, and Richard Johnston. 2008. "When Does Diversity Erode Trust? Neighbourhood Diversity, Interpersonal Trust and the Mediating Effect of Social Interactions." Political Studies 56:57-75.

Sturgis, Patrick, Ian Brunton-Smith, Sanna Read, and Nick Allum. 2011. "Does ethnic diversity erode trust?: Putnam's 'hunkering-down' thesis reconsidered." British Journal of Political Science 41(1):57-82.

Sønderskov, Kim M. 2011. "Explaining large-N cooperation: Generalized social trust and the social exchange heuristic." Rationality and Society 23(1):51-74.

Sønderskov, Kim M., and Peter Thisted Dinesen. Forthcoming. "Danish Exceptionalism: Explaining the Unique Increase in Social Trust over the Past 30 Years,” European Sociological Review.

Tajfel, Henry. 1981. Human Groups and Social Categories. Cambridge: Cambridge University Press.

Uslaner, Eric. 2002. The Moral Foundations of Trust. New York: Cambridge University Press.

Uslaner, Eric. 2012. Segregation and Mistrust. New York: Cambridge University Press.

Van der Meer, Tom and Jochem Tolsma. 2014. "Ethnic Diversity and Its Effects on Social Cohesion." Annual Review of Sociology 40: 459-78.

Wong, Cara, Jake Bowers, Tarah Williams, and Katherine Drake Simmons. 2012. "Bringing the Person Back In: Boundaries, Perceptions, and the Measurement of Racial Context." Journal of Politics 74(4):1153-70.

Wooldridge, Jeffrey M. 2013. Introductory Econometrics. Cengage Learning. 
Zmerli, Sonja and Kenneth Newton. 2008. "Social Trust and Attitudes Toward Democracy.” Public Opinion Quarterly 72(4):706-24. 
Table 1: The impact of ethnic diversity of the micro-context on social trust

\begin{tabular}{|c|c|c|c|}
\hline $\begin{array}{l}\text { Model } \\
\text { Measure of diversity }\end{array}$ & $\begin{array}{c}\text { I } \\
\text { Ethnic } \\
\text { Fragmentation }\end{array}$ & $\begin{array}{c}\text { II } \\
\text { Concentration of } \\
\text { Immigrants } \\
\end{array}$ & $\begin{array}{c}\text { III } \\
\text { Concentration } \\
\text { Non-Western ir }\end{array}$ \\
\hline \multicolumn{4}{|l|}{ Individual characteristics } \\
\hline Gender (male) & $\begin{array}{l}-0.44^{* * *} \\
(13.08)\end{array}$ & $\begin{array}{l}-0.44^{* * *} \\
(13.07)\end{array}$ & $\begin{array}{l}-0.44^{* * *} \\
(13.06)\end{array}$ \\
\hline Age (years) & $\begin{array}{l}0.01^{* * *} \\
(5.91)\end{array}$ & $\begin{array}{l}0.01^{* * * *} \\
(5.90)\end{array}$ & $\begin{array}{l}0.01^{* * *} \\
(5.88)\end{array}$ \\
\hline Education (years) & $\begin{array}{l}0.06^{* * *} \\
(8.69)\end{array}$ & $\begin{array}{l}0.06^{* * *} \\
(8.69)\end{array}$ & $\begin{array}{l}0.06^{* * *} \\
(8.67)\end{array}$ \\
\hline $\begin{array}{l}\text { Disposable yearly income } \\
\text { (mill. Danish kroner) }\end{array}$ & $\begin{array}{l}-0.10 \\
(1.09)\end{array}$ & $\begin{array}{l}-0.10 \\
(1.10)\end{array}$ & $\begin{array}{l}-0.10 \\
(1.12)\end{array}$ \\
\hline Unemployed (yes) & $\begin{array}{c}0.06 \\
(0.68)\end{array}$ & $\begin{array}{c}0.06 \\
(0.69)\end{array}$ & $\begin{array}{c}0.06 \\
(0.68)\end{array}$ \\
\hline Cohabitation (yes) & $\begin{array}{l}-0.07 \\
(1.69)\end{array}$ & $\begin{array}{l}-0.07 \\
(1.68)\end{array}$ & $\begin{array}{l}-0.07 \\
(1.65)\end{array}$ \\
\hline Length of residence (years) & $\begin{array}{c}0.00 \\
(1.19)\end{array}$ & $\begin{array}{c}0.00 \\
(1.18)\end{array}$ & $\begin{array}{c}0.00 \\
(1.18)\end{array}$ \\
\hline Victimization (yes) & $\begin{array}{l}-0.08 \\
(1.89)\end{array}$ & $\begin{array}{l}-0.08 \\
(1.90)\end{array}$ & $\begin{array}{l}-0.08 \\
(1.92)\end{array}$ \\
\hline Institutional trust $(0-10)$ & $\begin{array}{l}0.34^{* * *} \\
(25.05)\end{array}$ & $\begin{array}{l}0.34^{* * *} \\
(25.06)\end{array}$ & $\begin{array}{l}0.34^{* * *} \\
(25.05)\end{array}$ \\
\hline Life satisfaction $(0-10)$ & $\begin{array}{l}0.18^{* * *} \\
(12.54)\end{array}$ & $\begin{array}{l}0.18^{* * *} \\
(12.55)\end{array}$ & $\begin{array}{l}0.18^{* * *} \\
(12.55)\end{array}$ \\
\hline Contextual characteristics & & & \\
\hline Ethnic diversity & $\begin{array}{l}-0.42^{* * *} \\
(2.69)\end{array}$ & $\begin{array}{l}-0.65^{* *} \\
(2.81)\end{array}$ & $\begin{array}{l}-0.61^{*} \\
(2.42)\end{array}$ \\
\hline Mean level of education (years) & $\begin{array}{l}0.05^{* *} \\
(2.79)\end{array}$ & $\begin{array}{l}0.05^{* *} \\
(2.73)\end{array}$ & $\begin{array}{l}0.04^{*} \\
(2.54)\end{array}$ \\
\hline $\begin{array}{l}\text { Mean disposable yearly income } \\
\text { (mill. Danish Kroner) }\end{array}$ & $\begin{array}{l}-0.13 \\
(0.81)\end{array}$ & $\begin{array}{l}-0.13 \\
(0.82)\end{array}$ & $\begin{array}{l}-0.12 \\
(0.76)\end{array}$ \\
\hline Unemployment rate & $\begin{array}{c}0.24 \\
(1.03)\end{array}$ & $\begin{array}{c}0.27 \\
(1.15)\end{array}$ & $\begin{array}{c}0.21 \\
(0.91)\end{array}$ \\
\hline Single-parent households & $\begin{array}{c}0.07 \\
(0.74)\end{array}$ & $\begin{array}{c}0.07 \\
(0.70)\end{array}$ & $\begin{array}{c}0.07 \\
(0.70)\end{array}$ \\
\hline $\begin{array}{l}\text { Income inequality } \\
\text { (Gini coefficient) }\end{array}$ & $\begin{array}{c}0.30 \\
(1.55)\end{array}$ & $\begin{array}{c}0.29 \\
(1.51)\end{array}$ & $\begin{array}{c}0.26 \\
(1.37)\end{array}$ \\
\hline Crime incidents (100s) & $\begin{array}{c}0.00 \\
(1.01)\end{array}$ & $\begin{array}{c}0.00 \\
(1.05)\end{array}$ & $\begin{array}{c}0.00 \\
(1.10)\end{array}$ \\
\hline
\end{tabular}




\begin{tabular}{lccc} 
Residential turnover & -0.04 & -0.04 & -0.05 \\
Homeownership & $(0.40)$ & $(0.42)$ & $(0.48)$ \\
& 0.03 & 0.03 & 0.03 \\
Population density (number of & $(0.38)$ & $(0.42)$ & $(0.48)$ \\
residents within context) & 0.00 & -0.00 & -0.00 \\
ESS round (ref = 2002/3) & $(0.03)$ & $(0.03)$ & $(0.19)$ \\
$2004 / 5$ & & & \\
& $-0.21^{* * *}$ & $-0.21^{* * *}$ & $-0.21^{* * *}$ \\
$2006 / 7$ & $(3.73)$ & $(3.73)$ & $(3.71)$ \\
& -0.09 & -0.09 & -0.09 \\
$2008 / 9$ & $(1.58)$ & $(1.57)$ & $(1.58)$ \\
& -0.09 & -0.09 & -0.09 \\
$2010 / 11$ & $(1.76)$ & $(1.74)$ & $(1.77)$ \\
& -0.04 & -0.04 & -0.05 \\
Constant & $(0.81)$ & $(0.80)$ & $(0.85)$ \\
& $1.69^{* * *}$ & $1.70^{* * *}$ & $1.74 * * *$ \\
$\mathrm{~N}$ & $(6.91)$ & $(6.93)$ & $(7.02)$ \\
$\mathrm{R}-$ square & 6,543 & 6,543 & 6,543 \\
\hline
\end{tabular}

Notes: The table reports unstandardized OLS-regression coefficients with absolute t-values in parentheses (based on White-corrected standard errors). ***; **; $: \mathrm{p}<0.001 ; 0.01 ; 0.05$ (two-tailed test). The dependent variable, social trust, is scaled from 0 to 10 . 
Figure 1: The distribution of the three measures of ethnic diversity in contexts with a radius of 80 meters

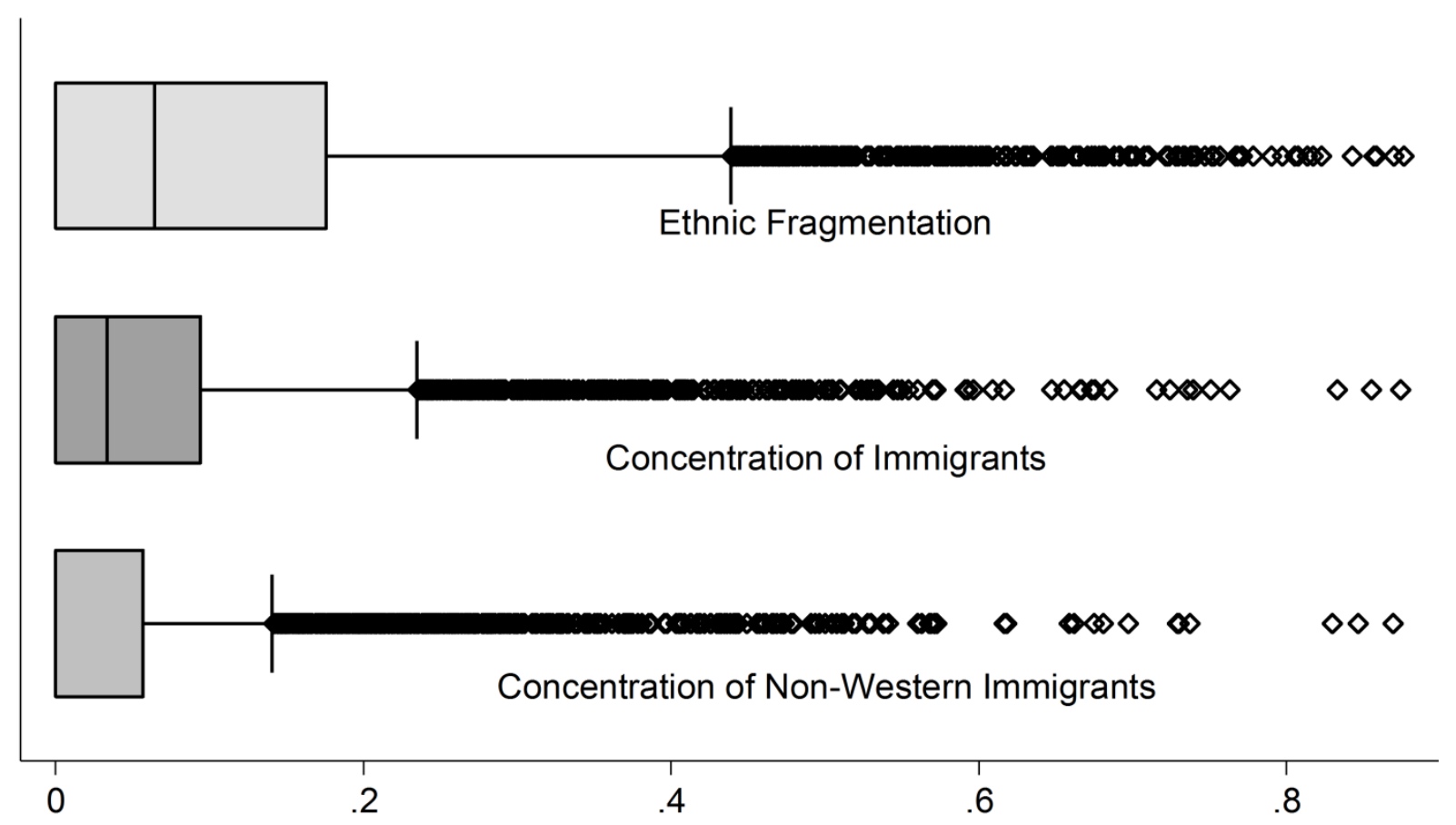

Note: The distribution is based on the 6,543 respondents included in the analyses reported in Table 1. The black vertical lines show the median, whereas the right hinges and the adjacent lines specify the 75. percentiles and the upper adjacent values, respectively. 
Figure 2: The effect of ethnic diversity estimated at different contextual sizes
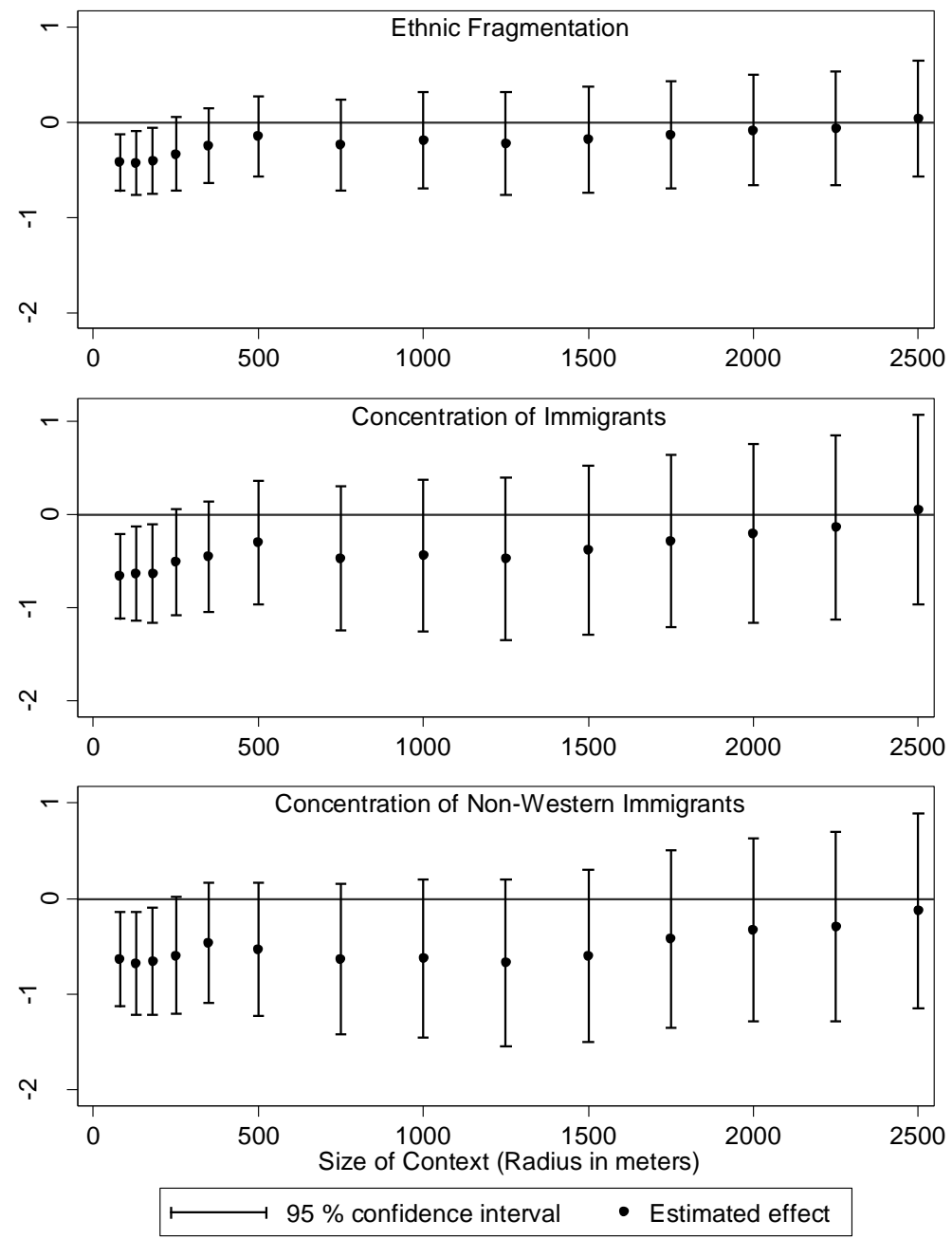


\section{Online supplement}

Table S1: Information about variables

\begin{tabular}{|c|c|c|c|}
\hline$\overline{\text { Variable }}$ & Coding/remarks & Mean/Std. dev & Source $^{b}$ \\
\hline \multicolumn{4}{|l|}{$\begin{array}{l}\text { Individual } \\
\text { characteristics }\end{array}$} \\
\hline Social trust & $\begin{array}{l}\text { Scale based on the following three questions: } \\
\text { - "Generally speaking, would you say that most people can be trusted, or that you can't } \\
\text { be too careful in dealing with people" } \\
\text { - "Do you think that most people would try to take advantage of you if they got the } \\
\text { chance, or would they try to be fair?" } \\
\text { - "Would you say that most of the time people try to be helpful or that they are mostly } \\
\text { looking out for themselves?" } \\
\text { All questions were measured on an eleven-point scale ranging from } 0 \text { ("You can't be too } \\
\text { careful"/“"Most people would try to take advantage of me"/“People mostly look out for } \\
\text { themselves") to } 10 \text { ("Most people can be trusted"/“Most people would try to be fair"/ } \\
\text { "People mostly try to be helpful"). } \\
\text { The final scale is calculated as the mean of the three items, thus running between } 0 \text { and } 10 \text {. } \\
\text { It only includes respondents having validly answered at least two of the three questions. } \\
\text { The scale has a Cronbach's alpha of } 0.71 \text {. }\end{array}$ & $6.82 / 1.53$ & $\begin{array}{l}\text { ESS (ppltrst, pplfair, } \\
\text { pplhlp) }\end{array}$ \\
\hline$\overline{\text { Gender (male) }}$ & $0=$ Female, $1=$ Male & $0.50 /-$ & Register data (koen) \\
\hline$\overline{\text { Age (years) }}$ & Age in years when interviewed. & $47.60 / 17.69$ & $\begin{array}{l}\text { Register data } \\
\text { (FOED_DAG)/ } \\
\text { ESS (inwyr/inwyys) }\end{array}$ \\
\hline Education (years) & $\begin{array}{l}\text { Years of full-time education completed. For most respondents, this is calculated as the time } \\
\text { required to obtain their highest level of education. For } 2.5 \% \text { of the sample (mainly older } \\
\text { respondents) this information is not present in the registers. In these cases, we use survey } \\
\text { data }\end{array}$ & $12.24 / 2.96$ & $\begin{array}{l}\text { Register data } \\
\text { (hfpria)/ESS (eduyrs) }\end{array}$ \\
\hline $\begin{array}{l}\text { Disposable yearly income } \\
\text { (mill. Danish Kroner) }\end{array}$ & $\begin{array}{l}\text { Disposable yearly income measured in million Danish kroner (indexed at } 2000 \text { level) in } \\
\text { year 2002, 2004, 2006, } 2008 \text { or } 2010^{c} \text {. }\end{array}$ & $0.16 / 0.15$ & $\begin{array}{l}\text { Register data } \\
\text { (DISPON_NY) }\end{array}$ \\
\hline
\end{tabular}




\begin{tabular}{|c|c|c|c|}
\hline Variable & Coding/remarks & Mean/Std. dev & Source $^{b}$ \\
\hline Unemployed (yes) & $\begin{array}{l}\text { Dummy variable indicating whether the respondent was unemployed for more than half a } \\
\text { year in } 2002,2004,2006,2008 \text { or } 2010^{c} \text {. }\end{array}$ & $0.04 /-$ & Register data (SOCIOO2) \\
\hline$\overline{\text { Cohabitation (yes) }}$ & $0=$ Single $; 1=$ Living with partner. & $0.69 /-$ & ESS (lvgptn/lvgptna) \\
\hline Victimization (yes) & $\begin{array}{l}\text { A dummy variable tapping whether the respondent or other members of their household } \\
\text { have been a victim of burglary or an assault within the last five years. }\end{array}$ & $0.25 /-$ & $\mathrm{ESS}(c r m v c t)$ \\
\hline $\begin{array}{l}\text { Length of residence } \\
\text { (years) }\end{array}$ & Years lived at current address at time of survey. & $14.25 / 16.17$ & $\begin{array}{l}\text { Register data } \\
\left(B O P \_V F R A\right) / \\
\text { ESS (inwyr/inwyys) }\end{array}$ \\
\hline Institutional trust $(0-10)$ & $\begin{array}{l}\text { A scale consisting of four items regarding trust in parliament, politicians, the legal system, } \\
\text { and the police. The scale has a Cronbach's alpha of } 0.79 \text { and is calculated as the mean of } \\
\text { the four items, thus running between } 0 \text { (lowest trust) - } 10 \text { (highest trust). It only includes } \\
\text { respondents having validly answered at least two of the four questions. }\end{array}$ & $6.75 / 1.55$ & $\begin{array}{l}\text { ESS (trstprl, trstlgl, } \\
\text { trstplc, trstplt) }\end{array}$ \\
\hline$\overline{\text { Life satisfaction }(0-10)}$ & $\begin{array}{l}\text { Response to the question "All things considered, how satisfied are you with your life as a } \\
\text { whole nowadays?" Scaled from } 0 \text { (Extremely dissatisfied) - } 10 \text { (Extremely satisfied). }\end{array}$ & $8.48 / 1.45$ & $\overline{E S S}$ (stflife) \\
\hline \multirow[t]{6}{*}{$\overline{\text { ESS round }}$} & Round that respondent participated in. & & ESS (essround) \\
\hline & - $\quad$ Round 1 & 0.20 & \\
\hline & - $\quad$ Round 2 & 0.20 & \\
\hline & - $\quad$ Round 3 & 0.19 & \\
\hline & - $\quad$ Round 4 & 0.21 & \\
\hline & - $\quad$ Round 5 & 0.20 & \\
\hline
\end{tabular}


- "Yes, several"

$0.07 /-$

- "Yes, a few"

$0.39 /-$

"No, none at all"

\begin{tabular}{|c|c|c|c|}
\hline Variable & Coding/remarks & Mean/Std. dev ${ }^{a}$ & Source $^{b}$ \\
\hline \multirow[t]{5}{*}{ Immigrant colleagues $^{\mathrm{f}}$} & $\begin{array}{l}\text { Response to the question "Do you have any colleagues at work who have come to live in } \\
\text { Denmark from another country?" with the following response categories: }\end{array}$ & & ESS, Round 1 (imgclg) \\
\hline & - "Yes, several" & $0.07 /-$ & \\
\hline & - "Yes, a few" & $0.34 /-$ & \\
\hline & - "No, none at all" & $0.38 /-$ & \\
\hline & - $\quad$ Not currently working & $0.21 /-$ & \\
\hline \multirow[t]{5}{*}{$\begin{array}{l}\text { Preferred ethnic mix of } \\
\text { residential } \text { area }^{\mathrm{g}}\end{array}$} & $\begin{array}{l}\text { The respondents were asked to indicate the preferred ethnic mix, choosing between the } \\
\text { following alternatives: }\end{array}$ & & ESS, Round 1 (idetalv) \\
\hline & $\begin{array}{l}\text { - "an area where almost nobody was of different race or ethnic group from most Danish } \\
\text { people" }\end{array}$ & $0.37 /-$ & \\
\hline & - "some people were of different race or ethnic group from most Danish people" & $0.36 /-$ & \\
\hline & - "Many people were of a different race or ethnic group". & $0.01 /-$ & \\
\hline & - $\quad$ "It would make no difference" & $0.27 /-$ & \\
\hline Moved $^{\mathrm{g}}$ & $\begin{array}{l}\text { Dummy variable indicating whether the respondent moved to another location within three } \\
\text { years after being surveyed. This measure is only calculated for respondents from ESS 1-4, } \\
\text { as this information was not yet available for ESS } 5 \text { at the time of writing of the paper. }\end{array}$ & $0.25 /-$ & $\begin{array}{l}\text { Register data } \\
(\text { BOP_VFRA)/ } \\
\text { ESS }(\text { inwyr/inwyys })\end{array}$ \\
\hline
\end{tabular}



\begin{tabular}{ll}
\hline Contextual & All contextual data are calculated using information about place of residence on January 1 in $2003,2005,2007,2009$ or 2011 ${ }^{\mathrm{d}}$. The \\
Characteristics & descriptive information is for contexts with a radius of 80 meters.
\end{tabular}

Ethnic diversity: The See also description in the text and Figure 1 for additional descriptive information.

three measures

- $\quad$ Ethnic fragmentation

The number of ethnic groups vary across contexts (Mean=4.72; $\mathrm{SD}=6.79)$

- Concentration of immigrants

$0.07 / 0.10$

- Concentration of non-Western immigrants

$0.05 / 0.09$

continues

\begin{tabular}{|c|c|c|c|}
\hline Variable & Coding/remarks & Mean/Std. dev ${ }^{a}$ & Source $^{b}$ \\
\hline Mean level of education & $\begin{array}{l}\text { Mean years of full time education completed. Data is missing for a fraction of (mainly } \\
\text { older) residents. We use the average of available observations. }\end{array}$ & $11.96 / 1.20$ & Register data (hfpria) \\
\hline $\begin{array}{l}\text { Mean disposable yearly } \\
\text { income } \\
\text { (mill. Danish Kroner) }\end{array}$ & $\begin{array}{l}\text { Mean disposable personal yearly income (in million Danish kroner) in 2002, 2004, 2006, } \\
2008 \text { or } 2010^{c} \text {. Indexed at 2000-level to adjust for inflation. Based on data on adults only. }\end{array}$ & $0.15 / 0.07$ & $\begin{array}{l}\text { Register data } \\
\left(D I S P O N \_N Y \text {, }\right. \\
\text { SOCIOO2) }\end{array}$ \\
\hline Unemployment rate & $\begin{array}{l}\text { Share of the adult population in the workforce, who were unemployed for more than half a } \\
\text { year in } 2002,2004,2006,2008,2010^{c} \text {. }\end{array}$ & $0.06 / 0.07$ & Register data (SOCIOO2) \\
\hline Single-parent households & Share of single-parent households. & $0.19 / 0.23$ & Register data $(\mathrm{K})$ \\
\hline $\begin{array}{l}\text { Income inequality } \\
\text { (Gini coefficient) }\end{array}$ & Gini coefficient calculated using disposable income and the ineqdec0 routine in Stata $\mathrm{h}$. & $0.28 / 0.09$ & $\begin{array}{l}\text { Register data } \\
\left(D I S P O N \_N Y\right)\end{array}$ \\
\hline Crime incidents (100s) & $\begin{array}{l}\text { The number of criminal verdicts (in 100s) of residents in the context plus the number of } \\
\text { crime victims in the context. Data are summed up over two years (either } 2002+2003 \text {, } \\
2004+2005,2006+2007,2008+2009 \text { or } 2010+2011)^{\mathrm{e}} \text {. }\end{array}$ & $7.90 / 13.78$ & $\begin{array}{l}\text { Register data } \\
\left(A F G \_G E R 7, A F G \_A F G\right. \\
\left.T Y P 3, O F R \_G E R 7\right)\end{array}$ \\
\hline Residential turnover & Share of current residents who moved into the context within a three-year period. & $0.28 / 0.20$ & $\begin{array}{l}\text { Register data } \\
\left(B O P_{-} V F R A\right)\end{array}$ \\
\hline Homeownership & Share of housing units within the context inhabited by the owner. & $0.65 / 0.40$ & $\begin{array}{l}\text { Register data } \\
\text { (UDLEJNINGSFOR- }\end{array}$ \\
\hline
\end{tabular}


Notes:

: All descriptives are based on the 6,543 respondents included in the analyses reported in Table 1 (or a subsample of respondents from ESS 1 ; see notes f and g below).

${ }^{\mathrm{b}}$ : Further information about the ESS variables, sampling and fieldwork can be found at http://ess.nsd.uib.no/. Information about the register data can be found at http://www.dst.dk/en/TilSalg/Forskningsservice.aspx and in Pedersen, C.B. (2011). "The Danish civil registration system.". Scandinavian Journal of Public Health 39:22-25.

': Depending on which year the respondent was surveyed: 2002 for respondents surveyed in 2002 or 2003,2004 for respondents surveyed in 2004 or 2005,2006 for respondents surveyed in 2006 or 2007, 2008 for respondents surveyed in 2008 or 2009, 2010 for respondents surveyed in 2010 or 2011.

d: Depending on which year the respondent was surveyed; 2003 for respondents surveyed in 2002 or 2003 and so on.

: Depending on which year the respondent was surveyed; 2002+2003 for respondents surveyed in 2002 or 2003 and so on.

f: This variable is only used in the analysis reported in the section on the potential moderating effect of interethnic contact on ethnic diversity.

$\mathrm{g}$ : This variable is only used in the analysis reported in the section on self-selection.

h: Jenkins, S.P. (1999). 'sg104: Analysis of income distributions'. Stata Technical Bulletin, vol. 48.

i: The number of residents within (selected) other sizes of contexts are 130 meters: 209, 180 meters: 373,250 meters: 889,500 meters: 2,975, 1,000 meters: 9,600, 1,500 meters: $18,831,2,000$ meters: $31,055,2,500$ meters: 45,563 . 
Table S2: The impact of ethnic diversity of the micro-context on social trust (sample including both natives and immigrants)

\begin{tabular}{|c|c|c|c|}
\hline $\begin{array}{l}\text { Model } \\
\text { Measure of diversity }\end{array}$ & $\begin{array}{c}\text { I } \\
\text { Ethnic } \\
\text { Fragmentation }\end{array}$ & $\begin{array}{c}\text { II } \\
\text { Concentration of } \\
\text { Immigrants } \\
\end{array}$ & $\begin{array}{c}\text { III } \\
\text { Concentration } \\
\text { Non-Western ir }\end{array}$ \\
\hline \multicolumn{4}{|l|}{ Individual characteristics } \\
\hline Gender (male) & $\begin{array}{l}-0.42^{* * *} \\
(12.70)\end{array}$ & $\begin{array}{l}-0.42^{* * *} \\
(12.69)\end{array}$ & $\begin{array}{l}-0.42^{* * *} \\
(12.68)\end{array}$ \\
\hline Age (years) & $\begin{array}{l}0.01^{* * * *} \\
(6.00)\end{array}$ & $\begin{array}{l}0.01^{* * * *} \\
(5.98)\end{array}$ & $\begin{array}{l}0.01^{* * * *} \\
(5.95)\end{array}$ \\
\hline Education (years) & $\begin{array}{l}0.06^{* * *} \\
(8.61)\end{array}$ & $\begin{array}{l}0.06^{* * *} \\
(8.58)\end{array}$ & $\begin{array}{l}0.06^{* * *} \\
(8.56)\end{array}$ \\
\hline $\begin{array}{l}\text { Disposable yearly income } \\
\text { (mill. Danish kroner) }\end{array}$ & $\begin{array}{l}-0.08 \\
(0.83)\end{array}$ & $\begin{array}{l}-0.08 \\
(0.81)\end{array}$ & $\begin{array}{l}-0.08 \\
(0.83)\end{array}$ \\
\hline Unemployed (yes) & $\begin{array}{c}0.07 \\
(0.85)\end{array}$ & $\begin{array}{c}0.07 \\
(0.88)\end{array}$ & $\begin{array}{c}0.07 \\
(0.88)\end{array}$ \\
\hline Cohabitation (yes) & $\begin{array}{l}-0.07 \\
(1.78)\end{array}$ & $\begin{array}{l}-0.07 \\
(1.77)\end{array}$ & $\begin{array}{l}-0.07 \\
(1.74)\end{array}$ \\
\hline Length of residence (years) & $\begin{array}{c}0.00 \\
(1.13)\end{array}$ & $\begin{array}{c}0.00 \\
(1.13)\end{array}$ & $\begin{array}{c}0.00 \\
(1.13)\end{array}$ \\
\hline Victimization (yes) & $\begin{array}{l}-0.08^{*} \\
(2.03)\end{array}$ & $\begin{array}{l}-0.08^{*} \\
(2.04)\end{array}$ & $\begin{array}{l}-0.08^{*} \\
(2.06)\end{array}$ \\
\hline Institutional trust $(0-10)$ & $\begin{array}{l}0.34^{* * *} \\
(25.93)\end{array}$ & $\begin{array}{l}0.34^{* * * *} \\
(25.93)\end{array}$ & $\begin{array}{l}0.34^{* * *} \\
(25.93)\end{array}$ \\
\hline Life satisfaction $(0-10)$ & $\begin{array}{l}0.18^{* * *} \\
(12.82)\end{array}$ & $\begin{array}{l}0.18^{* * *} \\
(12.86)\end{array}$ & $\begin{array}{l}0.18^{* * *} \\
(12.85)\end{array}$ \\
\hline Immigrant (yes) ${ }^{\#}$ & $\begin{array}{c}-0.33 * * * \\
(3.86)\end{array}$ & $\begin{array}{c}-0.31 * * * \\
(3.68)\end{array}$ & $\begin{array}{c}-0.32 * * * \\
(3.73)\end{array}$ \\
\hline Contextual characteristics & & & \\
\hline Ethnic diversity & $\begin{array}{l}-0.46^{* *} \\
(3.13)\end{array}$ & $\begin{array}{l}-0.73^{* * * *} \\
(3.48)\end{array}$ & $\begin{array}{l}-0.76^{* * * *} \\
(3.30)\end{array}$ \\
\hline Mean level of education (years) & $\begin{array}{l}0.05^{* *} \\
(2.77)\end{array}$ & $\begin{array}{l}0.04^{* *} \\
(2.68)\end{array}$ & $\begin{array}{l}0.04^{*} \\
(2.44)\end{array}$ \\
\hline $\begin{array}{l}\text { Mean disposable yearly income } \\
\text { (mill. Danish Kroner) }\end{array}$ & $\begin{array}{l}-0.11 \\
(0.71)\end{array}$ & $\begin{array}{l}-0.11 \\
(0.72)\end{array}$ & $\begin{array}{l}-0.10 \\
(0.62)\end{array}$ \\
\hline Unemployment rate & $\begin{array}{c}0.25 \\
(1.08)\end{array}$ & $\begin{array}{c}0.29 \\
(1.28)\end{array}$ & $\begin{array}{c}0.26 \\
(1.14)\end{array}$ \\
\hline Single-parent households & $\begin{array}{c}0.07 \\
(0.71)\end{array}$ & $\begin{array}{c}0.06 \\
(0.63)\end{array}$ & $\begin{array}{c}0.06 \\
(0.62)\end{array}$ \\
\hline $\begin{array}{l}\text { Income inequality } \\
\text { (Gini coefficient) }\end{array}$ & $\begin{array}{c}0.27 \\
(1.41)\end{array}$ & $\begin{array}{c}0.26 \\
(1.35)\end{array}$ & $\begin{array}{c}0.23 \\
(1.22)\end{array}$ \\
\hline Crime incidents (100s) & $\begin{array}{l}-0.00 \\
(0.10)\end{array}$ & $\begin{array}{c}0.00 \\
(0.01)\end{array}$ & $\begin{array}{c}0.00 \\
(0.16)\end{array}$ \\
\hline
\end{tabular}




\begin{tabular}{lccc} 
Residential turnover & -0.03 & -0.03 & -0.04 \\
Homeownership & $(0.33)$ & $(0.34)$ & $(0.45)$ \\
& 0.06 & 0.06 & 0.06 \\
Population density (number of & $(0.82)$ & $(0.87)$ & $(0.86)$ \\
residents within context) & 0.00 & 0.00 & 0.00 \\
ESS round (ref = 2002/3) & $(1.37)$ & $(1.27)$ & $(1.06)$ \\
$2004 / 5$ & & & $-0.19^{* * *}$ \\
& $-0.19^{* * *}$ & $-0.19^{* * * *}$ & $(3.53)$ \\
$2006 / 7$ & $(3.53)$ & $(3.51)$ & -0.08 \\
& -0.08 & -0.08 & $(1.51)$ \\
$2008 / 9$ & $(1.53)$ & $(1.50)$ & -0.08 \\
& -0.08 & -0.08 & $(1.45)$ \\
$2010 / 11$ & $(1.47)$ & $(1.44)$ & -0.02 \\
& -0.02 & -0.01 & $(0.32)$ \\
Constant & $(0.29)$ & $(0.28)$ & $1.80^{* * * *}$ \\
& $1.74^{* * *}$ & $1.75^{* * *}$ & $(7.46)$ \\
\hline $\mathrm{N}$ & $(7.27)$ & $(7.32)$ & 6,906 \\
$\mathrm{R}$-square & 6,906 & 6,906 & 0.23
\end{tabular}

Notes: The table reports unstandardized OLS-regression coefficients with absolute $t$-values in parentheses (based on White-corrected standard errors). ***; **; *: p < 0.001; 0.01; 0.05 (two-tailed test). ${ }^{\#}:$ The immigrant category comprises immigrants and descendants. The dependent variable, social trust, is scaled from 0 to 10 . 
Table S3: The impact of ethnic diversity of the micro-context on social trust (sample excluding respondents with contextual information based on less than 20 individuals)

\begin{tabular}{|c|c|c|c|}
\hline $\begin{array}{l}\text { Model } \\
\text { Measure of diversity }\end{array}$ & $\begin{array}{c}\text { I } \\
\text { Ethnic } \\
\text { Fragmentation }\end{array}$ & $\begin{array}{c}\text { II } \\
\text { Concentration of } \\
\text { Immigrants }\end{array}$ & $\begin{array}{c}\text { III } \\
\text { Concentration of } \\
\text { Non-Western imm. }\end{array}$ \\
\hline \multicolumn{4}{|l|}{ Individual characteristics } \\
\hline Gender (male) & $\begin{array}{l}-0.44^{* * *} \\
(11.87)\end{array}$ & $\begin{array}{l}-0.44^{* * *} \\
(11.87)\end{array}$ & $\begin{array}{l}-0.44^{* * *} \\
(11.86)\end{array}$ \\
\hline Age (years) & $\begin{array}{l}0.01^{* * *} \\
(4.93)\end{array}$ & $\begin{array}{l}0.01^{* * *} \\
(4.93)\end{array}$ & $\begin{array}{l}0.01^{* * *} \\
(4.92)\end{array}$ \\
\hline Education (years) & $\begin{array}{l}0.06^{* * * *} \\
(7.40)\end{array}$ & $\begin{array}{l}0.06^{* * * *} \\
(7.41)\end{array}$ & $\begin{array}{l}0.06^{* * *} \\
(7.40)\end{array}$ \\
\hline $\begin{array}{l}\text { Disposable yearly income } \\
\text { (mill. Danish kroner) }\end{array}$ & $\begin{array}{c}0.01 \\
(0.06)\end{array}$ & $\begin{array}{c}0.01 \\
(0.06)\end{array}$ & $\begin{array}{c}0.01 \\
(0.03)\end{array}$ \\
\hline Unemployed (yes) & $\begin{array}{c}0.08 \\
(0.78)\end{array}$ & $\begin{array}{c}0.08 \\
(0.79)\end{array}$ & $\begin{array}{c}0.08 \\
(0.79)\end{array}$ \\
\hline Cohabitation (yes) & $\begin{array}{l}-0.09^{*} \\
(1.97)\end{array}$ & $\begin{array}{l}-0.09^{*} \\
(1.97)\end{array}$ & $\begin{array}{l}-0.09 \\
(1.93)\end{array}$ \\
\hline Length of residence (years) & $\begin{array}{c}0.00 \\
(1.14)\end{array}$ & $\begin{array}{c}0.00 \\
(1.14)\end{array}$ & $\begin{array}{c}0.00 \\
(1.13)\end{array}$ \\
\hline Victimization (yes) & $\begin{array}{l}-0.08 \\
(1.89)\end{array}$ & $\begin{array}{l}-0.08 \\
(1.89)\end{array}$ & $\begin{array}{l}-0.08 \\
(1.91)\end{array}$ \\
\hline Institutional trust $(0-10)$ & $\begin{array}{l}0.34^{* * * *} \\
(22.99)\end{array}$ & $\begin{array}{l}0.34^{* * * *} \\
(23.00)\end{array}$ & $\begin{array}{l}0.34^{* * *} \\
(23.00)\end{array}$ \\
\hline Life satisfaction $(0-10)$ & $\begin{array}{l}0.19^{* * *} \\
(11.71)\end{array}$ & $\begin{array}{l}0.19^{* * * *} \\
(11.72)\end{array}$ & $\begin{array}{l}0.19^{* * *} \\
(11.71)\end{array}$ \\
\hline Contextual characteristics & & & \\
\hline Ethnic diversity & $\begin{array}{l}-0.38^{*} \\
(2.18)\end{array}$ & $\begin{array}{l}-0.63^{*} \\
(2.39)\end{array}$ & $\begin{array}{l}-0.57^{*} \\
(2.03)\end{array}$ \\
\hline Mean level of education (years) & $\begin{array}{c}0.04 \\
(1.59)\end{array}$ & $\begin{array}{c}0.04 \\
(1.53)\end{array}$ & $\begin{array}{c}0.03 \\
(1.39)\end{array}$ \\
\hline $\begin{array}{l}\text { Mean disposable yearly income } \\
\text { (mill. Danish Kroner) }\end{array}$ & $\begin{array}{c}0.31 \\
(0.54)\end{array}$ & $\begin{array}{c}0.31 \\
(0.53)\end{array}$ & $\begin{array}{c}0.34 \\
(0.59)\end{array}$ \\
\hline Unemployment rate & $\begin{array}{l}0.15 \\
(0.37)\end{array}$ & $\begin{array}{c}0.22 \\
(0.54)\end{array}$ & $\begin{array}{c}0.12 \\
(0.30)\end{array}$ \\
\hline Single-parent households & $\begin{array}{l}-0.00 \\
(0.01)\end{array}$ & $\begin{array}{l}-0.01 \\
(0.07)\end{array}$ & $\begin{array}{l}-0.00 \\
(0.04)\end{array}$ \\
\hline $\begin{array}{l}\text { Income inequality } \\
\text { (Gini coefficient) }\end{array}$ & $\begin{array}{c}0.24 \\
(0.86)\end{array}$ & $\begin{array}{c}0.24 \\
(0.86)\end{array}$ & $\begin{array}{c}0.19 \\
(0.70)\end{array}$ \\
\hline Crime incidents (100s) & $\begin{array}{c}0.00 \\
(0.99)\end{array}$ & $\begin{array}{c}0.00 \\
(1.02)\end{array}$ & $\begin{array}{c}0.00 \\
(1.08)\end{array}$ \\
\hline Residential turnover & -0.05 & -0.05 & -0.06 \\
\hline
\end{tabular}




\begin{tabular}{lccc} 
& $(0.37)$ & $(0.40)$ & $(0.45)$ \\
Homeownership & -0.03 & -0.02 & -0.02 \\
Population density (number of & $(0.31)$ & $(0.28)$ & $(0.24)$ \\
residents within context) & 0.00 & 0.00 & -0.00 \\
ESS round (ref = 2002/3) & $(0.04)$ & $(0.01)$ & $(0.13)$ \\
$2004 / 5$ & & & $-0.24^{* * *}$ \\
& $-0.24^{* * *}$ & $-0.24^{* * *}$ & $(3.98)$ \\
$2006 / 7$ & $(3.99)$ & $(3.98)$ & -0.09 \\
& -0.09 & -0.09 & $(1.56)$ \\
$2008 / 9$ & $(1.57)$ & $(1.54)$ & $-0.12^{*}$ \\
& $-0.12^{*}$ & $-0.12^{*}$ & $(2.11)$ \\
$2010 / 11$ & $(2.10)$ & $(2.05)$ & -0.09 \\
& -0.09 & -0.09 & $(1.56)$ \\
Constant & $(1.53)$ & $(1.51)$ & $1.89^{* * *}$ \\
& $1.84^{* * *}$ & $1.85^{* * *}$ & $(6.23)$ \\
\hline $\mathrm{N}$ & $(6.14)$ & $(6.17)$ & 5,572 \\
$\mathrm{R}-$ square & 5,572 & 5,572 & 0.23 \\
\hline
\end{tabular}

Notes: The table reports unstandardized OLS-regression coefficients with absolute t-values in parentheses (based on White-corrected standard errors). $* * * ; * ; *: \mathrm{p}<0.001 ; 0.01 ; 0.05$ (two-tailed test). The dependent variable, social trust, is scaled from 0 to 10 . 
Figure S1: The development in the share of immigrants across Western Europe (1990-2010)
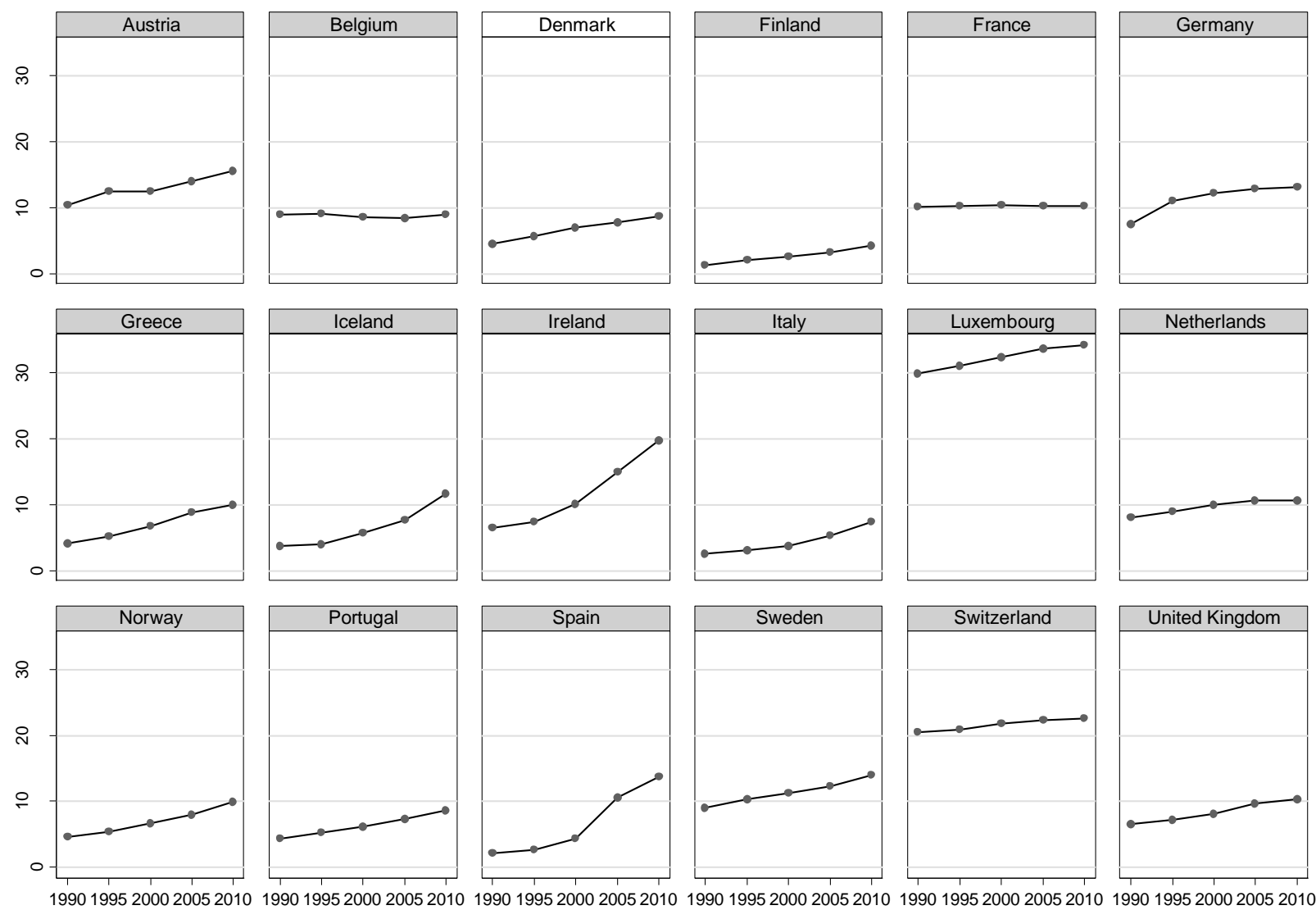

Year

Source: World Development Indicators from The World Bank. 
Figure S2: Mean levels of Anti-Foreigner Sentiments across Western Europe (2002-2011)

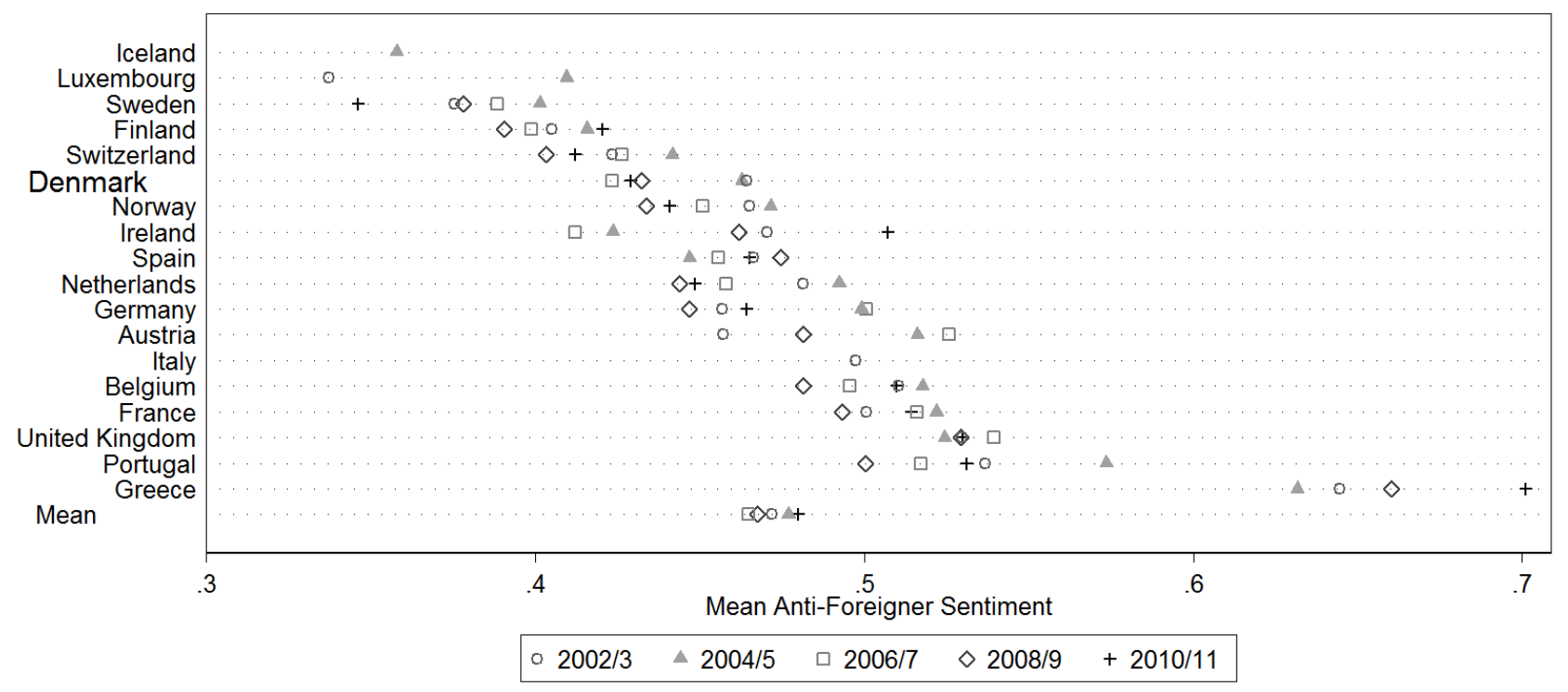

Note: Anti-Foreigner Sentiments are measured with a scale based on the following three questions: "Would you say it is generally bad or good for [country]'s economy that people come to live here from other countries?"; "Would you say that [country]'s cultural life is generally undermined or enriched by people coming to live here from other countries?"; "Is [country] made a worse or a better place to live by people coming to live here from other countries?". All questions were answered on a 0-10 scale, which has been rescaled, to range between 0 and 1 , and reversed, so high values correspond to high levels of anti-foreigner sentiments. Only respondents answering at least two of the questions are included. The data are weighted to correct for sampling bias. Source: European Social Survey, Round 1-5. 
Figure S3: Augmented plus residual plots
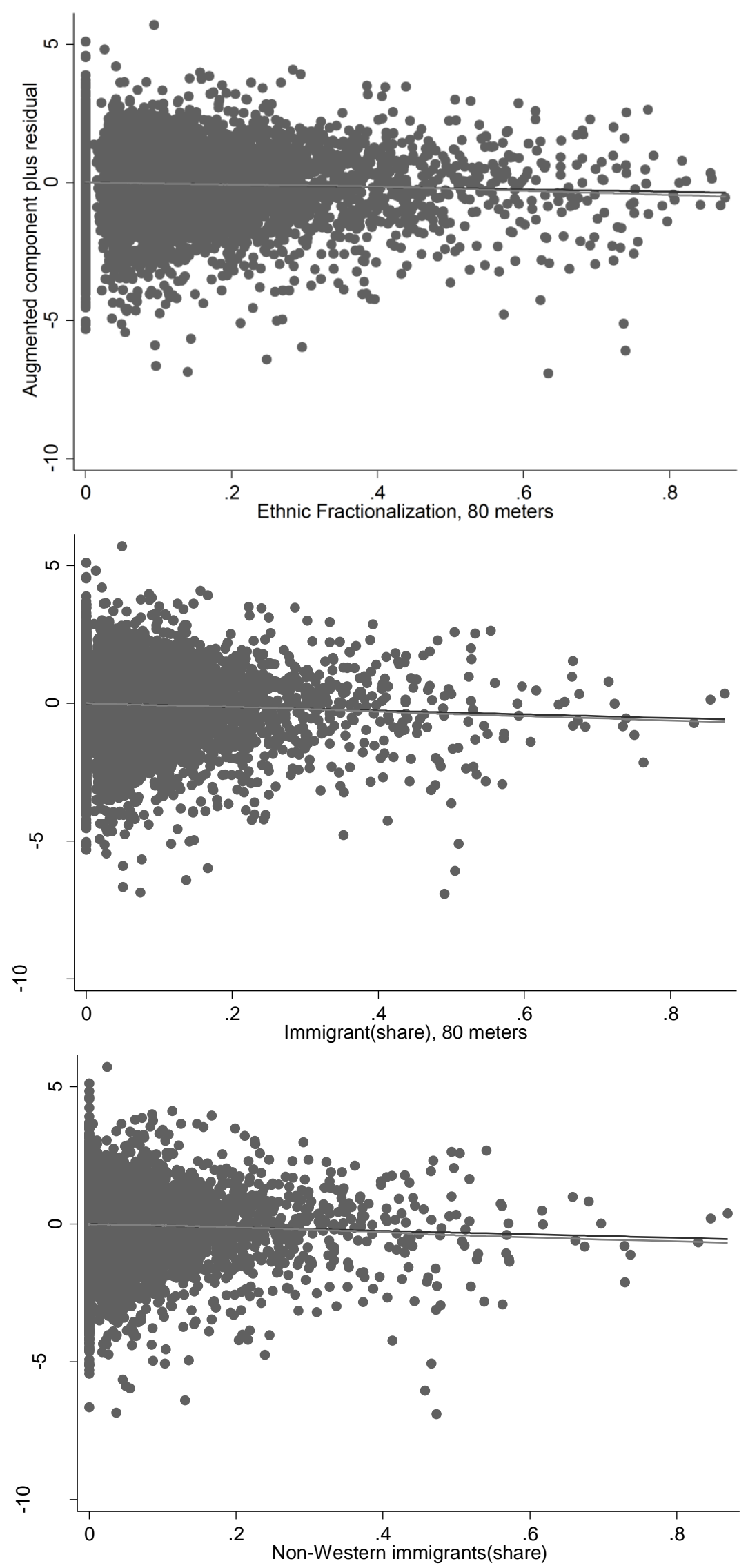

Note: This figure is motivated in note 14 in the manuscript. The dark lines are the reference lines while the light lines are lowess lines. 